\title{
WestVirginiaUniversity
}

THE RESEARCH REPOSITORY @ WVU

Graduate Theses, Dissertations, and Problem Reports

2008

\section{Delayed disruption of temporally controlled behavior}

\author{
Mirari Elcoro \\ West Virginia University
}

Follow this and additional works at: https://researchrepository.wvu.edu/etd

\section{Recommended Citation}

Elcoro, Mirari, "Delayed disruption of temporally controlled behavior" (2008). Graduate Theses, Dissertations, and Problem Reports. 2691.

https://researchrepository.wvu.edu/etd/2691

This Dissertation is protected by copyright and/or related rights. It has been brought to you by the The Research Repository @ WVU with permission from the rights-holder(s). You are free to use this Dissertation in any way that is permitted by the copyright and related rights legislation that applies to your use. For other uses you must obtain permission from the rights-holder(s) directly, unless additional rights are indicated by a Creative Commons license in the record and/ or on the work itself. This Dissertation has been accepted for inclusion in WVU Graduate Theses, Dissertations, and Problem Reports collection by an authorized administrator of The Research Repository @ WVU.

For more information, please contact researchrepository@mail.wvu.edu. 
Delayed Disruption of Temporally Controlled Behavior

Mirari Elcoro

\author{
Dissertation Submitted to the \\ Eberly College of Arts and Sciences \\ at West Virginia University \\ in partial fulfillment of the requirements \\ for the degree of \\ Doctor of Philosophy \\ in \\ Psychology
}

Department of Psychology

Morgantown, West Virginia

2008

Kennon A. Lattal, Ph.D., Chair

Karen G. Anderson, Ph.D.

Daniel Hursh, Ph.D.

Joseph R. Scotti, Ph.D.

Claire St. Peter Pipkin, Ph.D.

Keywords: temporal control, resistance to change, response-independent food, pigeons, keypeck 


\section{ABSTRACT \\ Delayed Disruption of Temporally Controlled Behavior \\ Mirari Elcoro}

Delivery of response-independent food during intertrial intervals (ITI) of fixed-interval (FI) schedules was used to examine the resistance to change of temporal control in pigeons. After response rates stabilized on an FI $150 \mathrm{~s}$ ITI $135 \mathrm{~s}$, response-independent food was delivered at the beginning of the ITI in one condition and at the end of the ITI in a separate condition (Experiment 1). The ITI then was shortened to $35 \mathrm{~s}$ and the same conditions were examined. In Experiment 2, these same conditions were examined, but with responding maintained by an FI 30-s schedule. Differential effects of food location were not obtained in either experiment. The results are discussed in relation to such parameters as delay of disruption, disrupter frequency, ITI duration and general resistance to change of FI schedules. 


\section{Acknowledgements}

I thank Andy for his infinite patience, inspiration, and friendship throughout my graduate career. I thank Karen G. Anderson for being my mentor during these five years. I thank Scotti for his attention to detail and dedication to science. I thank Claire for her interest in my dissertation topic, her ideas to make this dissertation better, and her availability. I thank Dan Hursh for providing enlightening relations between basic and applied behavior analysis during the dissertation meetings.

I thank my friends: Chata Dickson, Raquel Aló, Harold Lobo, Jessica Long, James Diller, Yusuke Hayashi, Megan Maxwell, Carlos Cançado, and Toshi Kuroda. We all have had interesting and productive discussions concerning conceptual, analytical, and empirical issues in behavior analysis that have positively influenced this work. You all have been of incredible value for the completion of this manuscript.

I thank my family for supporting all my decisions. I thank Jeff for his love, for understanding me, for providing me with perspective when I have felt lost, and for making me feel at home. 
Table of Contents

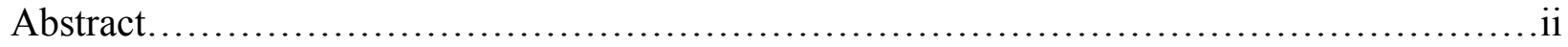

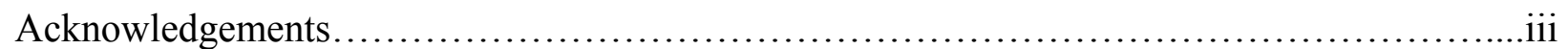

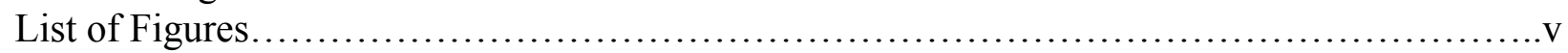

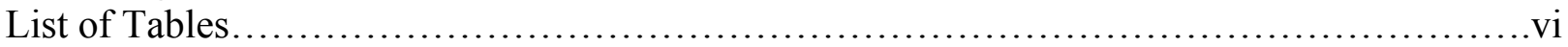

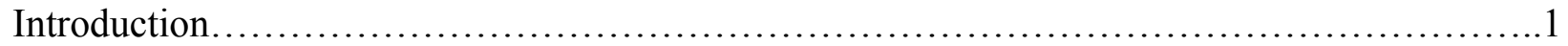

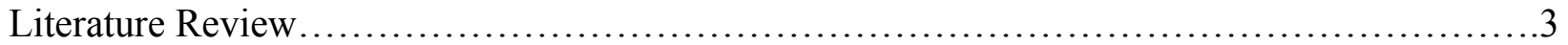

Definition of Temporal Control............................................. 3

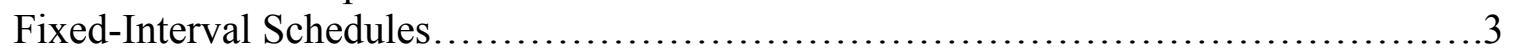

Analysis of Temporal Control...............................................5

Disrupters of Temporal Control...............................................6

Contextual Variables......................................................

Response-Independent Exteroceptive Stimuli............................9

Intertrial Intervals ..........................................

Changes in Houselight and Keylight Illumination...................12

Delivery of Response-Independent Food..........................14

Delay-of-Disruption Gradients.................................................. 18

Statement of the Problem........................................................... 19

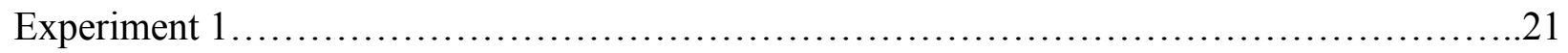

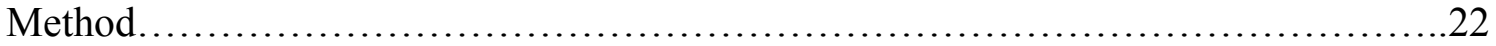

Subjects.........................................................22

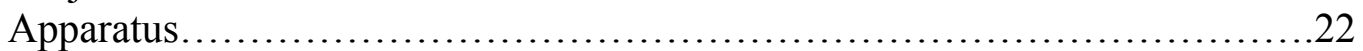

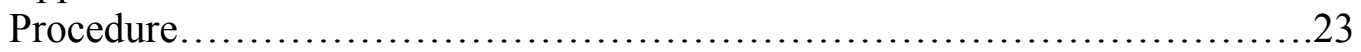

Results...................................................................25

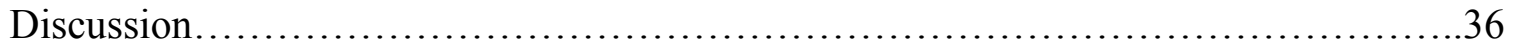

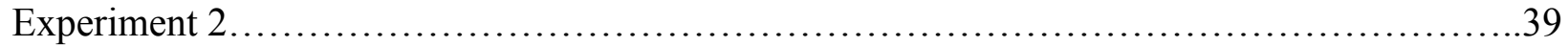

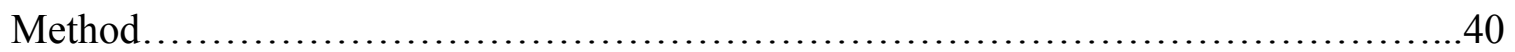

Subjects..........................................................40

Apparatus..........................................................40

Procedure................................................................. 40

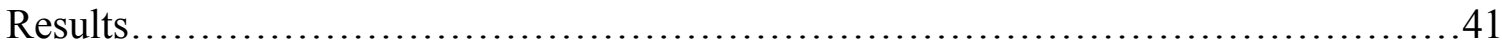

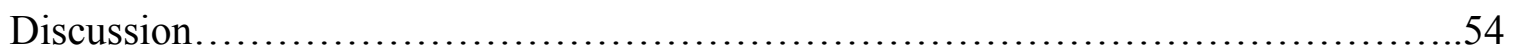

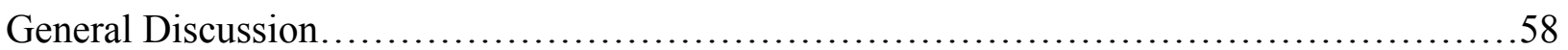

Fixed-Interval Schedules.................................................59

Delays Between Response-Independent Food and Temporally Controlled Responding...61

Delay-of-Disruption Gradients.........................................61

Response-Independent Food Delivery....................................62

Effects of ITI/ICI Duration....................................................64

Baseline Differences: Overall Response Rates and Patterns.........................65

Implications of the Results for the Study of Complex Operants.................... 67

Response Patterns as Behavioral Units....................................67

Application of Delay-of-Disruption Gradients............................... 70

Conclusion........................................................................... 71

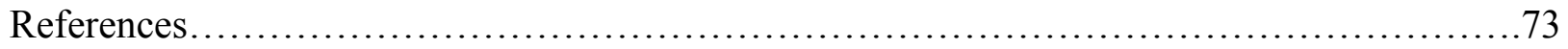




\section{List of Figures}

Figure 1. Overall response rates measured in response per $\min (\mathrm{Resp} / \mathrm{min})$ over the course of

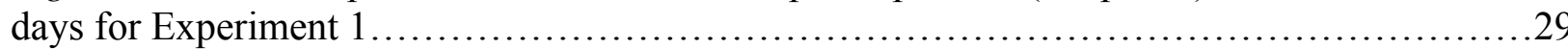

Figure 2. Log-transformed percent change from baseline based on overall response rates (y axis)

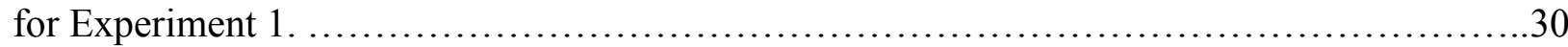

Figure 3. Log-transformed percent change from baseline based on PRPs measured in seconds (s)

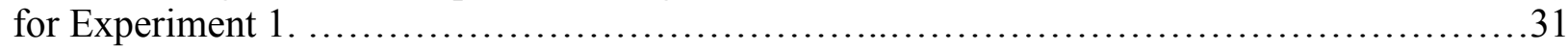

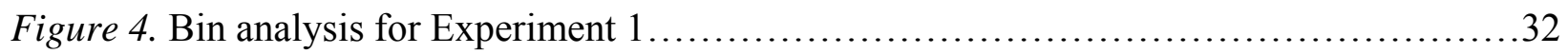

Figure 5. Overall response rates measured in responses per minute (Resp/min) over the course of

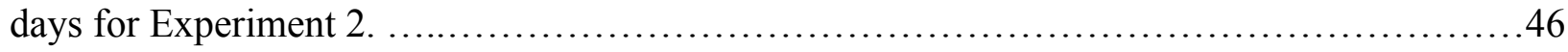

Figure 6. Log-transformed percent change from baseline based on overall response rates (y axis)

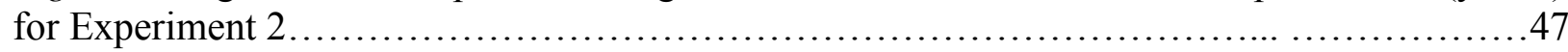

Figure 7. Log-transformed percent change from baseline based on PRPs measured in seconds (s)

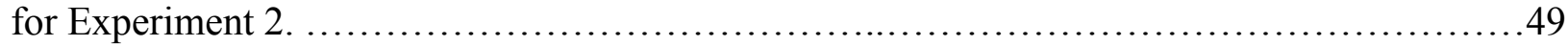

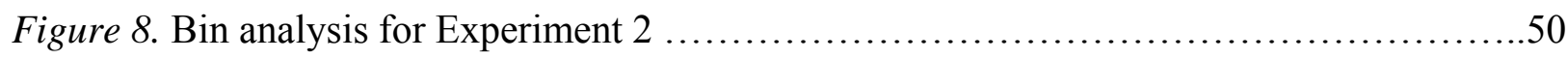

Figure 9. Hypothetical representation of disruption levels (y axis) as a function of ITI duration (x

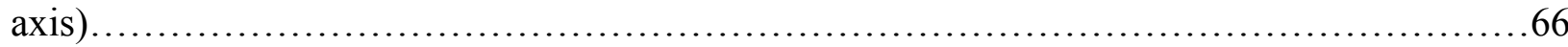




\section{List of Tables}

Table 1: Experimental conditions in order of presentation, number of sessions, mean overall response rates for the first six sessions in which response-independent food was delivered, mean overall response rates for the last six days of all conditions, mean PRP, and average

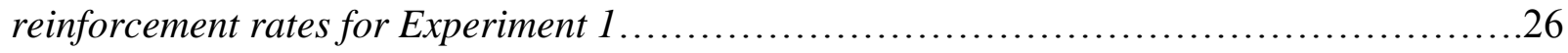

Table 2: Experimental conditions in order of presentation, number of sessions. Mean overall response rates for the first six sessions in which response-independent food was delivered, mean overall response rates for the last six days in all conditions), mean PRPs, and average reinforcement rates for Experiment 2.

Table 3: Quarter-life values for each pigeon calculated for the last session of Baseline, First and Last sessions of response-independent food delivered at the Beginning and End of the ITI of Experiment 1.

Table 4: Quarter-life values for each pigeon calculated for the last session of Baseline, First and Last sessions of response-independent food delivered at the Beginning and End of the ITI of Experiment 2.

Table 5: Percent change from baseline based on QL values for each pigeon, grouped by Experiment, for the last day of each baseline condition, the first and last sessions of each experimental condition (Beginning and End)... 
The strength of operant behavior has been defined in terms of its resistance to change when disruptive events precede or accompany such behavior (Nevin, 1974, 1979). Procedures such as the delivery of response-independent food, extinction, and prefeeding have been used to test the resistance of responding to change. Resistance to change typically has been assessed by comparing the response rates of two or more components of a multiple schedule against their corresponding baseline levels after one of the previously mentioned tests has been implemented. Response rate, however, is not the only measure of an operant (e.g., Gilbert, 1958). Effects of stimulus changes on other dimensions or parameters of the operant remain relatively unexamined. For example, some investigators (e.g., Hawkes \& Shimp, 1975; Zeiler, 1986) have considered the operant to be extended in time, incorporating patterns of responses. These patterns often are organized in relation to the temporal distributions of reinforcers, as in fixedinterval (FI) schedules. Such patterns of behavior resulting from these temporal distributions of reinforcers may be considered a complex form of the operant (Skinner, 1935). Like simple operants, a complex operant may be differentially resistant to change as a function of the prevailing reinforcement contingencies. The purpose of the present experiments was to examine the resistance to change of such temporally controlled responding.

The resistance of operant behavior to change has been assessed by imposing stimulus changes either directly or indirectly. Direct changes in stimuli are imposed while the operant behavior is occurring, as in extinction, delays of reinforcement, and the delivery of responseindependent food superimposed on schedules of reinforcement. Indirect assessment of resistance to change involves changes that are temporally distal from the operant behavior under study. These indirect procedures include prefeeding and the delivery of response-independent food 
during intertrial intervals (ITIs) in trial-based procedures and intercomponent intervals (ICIs) in multiple schedules.

Delays of reinforcement are considered a direct assessment of resistance of responding to change because they are imposed while operant behavior is occurring. Such delays increase the temporal separation between the operant response and the delivery of the reinforcer. The effects of delay of reinforcement are most commonly measured as changes in response rates. As the delay between response and reinforcer increases, response rates tend to decrease; a relation described as a delay-of-reinforcement gradient. Delay-of-reinforcement gradients have been replicated numerous times under a variety of conditions of reinforcement (e.g., Reilly \& Lattal, 2004; Richards, 1981; Schaal \& Branch, 1990; Sizemore \& Lattal, 1978). Delays imposed between events other than responses and reinforcers also may disrupt operant behavior. For example, the disrupted performance that results from delays of reinforcement parallels the disrupted performance that results from delays between sample and choice stimulus presentations in conditional discrimination procedures (e.g., Nevin, Milo, Odum, \& Shahan, 2003; Schaal, Odum, \& Shahan, 2000). Delays between events also may affect the patterns of responding observed in procedures designed to assess temporal control (Elcoro, 2005).

The purpose of the present experiments was to further examine the resistance to change of temporal control developed in FI schedules as a function of the temporal location of responseindependent food within ITIs. The following literature review first provides a description of basic concepts and measures of temporal control. This is followed by a review of the effects of contextual variables, and response-independent exteroceptive stimuli (e.g., lights, blackouts, food) on temporal control. Finally, the concept of delay-of-disruption gradients is defined and related to earlier studies of such gradients. 


\section{LITERTURE REVIEW}

\section{Definition of Temporal Control}

Temporal control is defined as behavioral control based on temporal properties of stimuli (Catania, 1991). Such control is evidenced by differentiated operant responding after repeated exposure to periodic reinforcement during transitional or steady-state responding (Higa, 1998; Staddon, Cheralu, \& Higa, 2002). Temporal control also has been referred to as timing; however, hereafter only the former term will be used because it is less susceptible to agency and reification than the latter term. That is, temporal control can be related directly to the control exerted by events or stimuli in the environment, as opposed to the term timing, which has been commonly equated to an internal mechanism used by the organism to govern its own behavior (e.g., Gibbon, 1977).

Procedures such as FI schedules, differential-reinforcement-of-low-rates (DRL) schedules, the peak-interval procedure (PIP), and the free-operant psychophysical procedure (FOPP) have been used to investigate temporal control. Fixed-interval schedules were the subject of the present analysis of temporal control because in previous experiments they have generated responding sensitive to disruptive operations. More specifically, patterns of responding generated by FI schedules have been systematically changed as a function of the delivery of responseindependent food (Lattal \& Bryan, 1976). Likewise, response patterns generated with the FOPP (Lieving, 2003) and the PIP (Elcoro, 2005; Grace \& Nevin, 2000) have also been differentially affected by the delivery of response-independent food.

Fixed-Interval Schedules

In an FI schedule, the first response after a fixed period of time has elapsed is reinforced (Ferster \& Skinner, 1957). One characteristic response pattern that emerges under an FI 
schedule, labeled the FI scallop, is an initial pause in responding following the delivery of a reinforcer (i.e., postreinforcement pause [PRP]), followed by a progressive increase in response rate as the time for the next delivery of the reinforcer approaches (Dews, 1970; Skinner, 1938). The break-and-run is another pattern that emerges after extended exposure to FI schedules (Cumming \& Schoenfeld, 1958; Schneider, 1969). This latter pattern is considered a variant of the FI scallop (Dews, 1978) and it consists of a short pause after the reinforcer delivery followed by more or less steady, high-rate responding throughout the interval until the next reinforcer is delivered. Both of these patterns, the scallop and break-and-run can be described as positively accelerated response patterns (Lattal \& Abreu-Rodrigues, 1997).

Dews $(1970,1978)$ suggested that temporally controlled patterns of responding during FI schedules emerge due to different delays between responses at different points in the FI and the reinforcer. Dews also proposed that response chaining was an underlying mechanism responsible for temporal control. In response chaining, one response during the FI serves as a discriminative stimulus for the occurrence of the next response (Wearden \& Lejeune, 2006).

During the 1970s, the study of temporal control with schedules of reinforcement underwent a shift to the study of more cognitive terms (Zeiler, 1986) currently evident in extensions of the Scalar Expectancy Theory of Timing (Gibbon, 1977) and the Behavioral Theory of Timing (Killeen \& Fetterman, 1988). The focus of this dissertation will be, as stated earlier, be on a behavioral perspective, thus the previously mentioned theories will not be elaborated. Wearden and Lejeune (2006) made a recent attempt to revive the interpretation by Dews (1970) of the development of response patterns in FI schedules using the idea of delay of reinforcement previously described. 
There are several procedures to analyze temporal control (for an extensive review see Richelle \& Lejeune, 1980). The following section describes the most commonly used indices of temporal control, some of which were used to analyze the data obtained in the present experiments.

\section{Analysis of Temporal Control}

A basic measure of temporal control is the PRP. The PRP is the time from the offset of the previous reinforcer to the first response in the next interval (in some instances rather than the first response, some other response, for example the fifth after the reinforcer, serves to demarcate the end of the PRP). The PRP is proportional to the value of the FI: as the value of the FI increases, so does the PRP (Higa \& Pierson, 1998; Innis, Mitchell, \& Staddon, 1993).

The distribution of responses during an FI schedule can be summarized quantitatively using the quarter life $(\mathrm{QL})$. The $\mathrm{QL}$ is the percentage of the FI required for the emission of 25\% of the total responses. A QL value lower than 0.25 , indicates that more than $25 \%$ of the responses occurred in this quarter of the interval. A value greater than 0.25 , indicates that less than $25 \%$ of the responses occurred in the first quarter of the interval (Gollub, 1964; Herrnstein \& Morse, 1957; Zeiler \& Powell, 1994). For example, a QL of 0.10 indicates that $25 \%$ of the total amount of responses during that interval occurred during the first tenth of that interval.

The index of curvature (IC) is another summary measure of the distribution of responses along the FI. The IC reflects the extent and direction of the difference between the data obtained in the distribution of responding across time segments of the interval (Fry, Kelleher, \& Cook, 1960; Gollub, 1964). Gollub defined the IC as the fraction resulting from the difference between the area under the constant rate cumulative curve and the area under the obtained curve, divided by the area under the constant rate cumulative curve. There is a high positive correlative between 
the QL and the IC. According to Gollub both indices provide an adequate summary of temporal control and may be used interchangeably.

A more detailed analysis of the distribution of responses in time in FI schedules is possible through a bin analysis, which entails examining the number of responses across successive 1-s periods (bins) of each FI during one session. This analysis allows visualizing how many responses were emitted during each 1-s bin in all FIs in one session. Both response rates and patterns were examined in the present experiments as a function of the location of the delivery of response-independent food.

\section{Disrupters of Temporal Control}

The terms disrupter and disruption are commonly used in the analysis of resistance to change (Nevin, 1974 et seq.). When procedural changes imposed on operant behavior such as prefeeding, extinction, delay of reinforcement, and delivery of response-independent food (Nevin, 1979) cause a change in responding, they are labeled disrupters. Whether imposed directly or indirectly on operant behavior, disrupters are assessed relative to a previous condition wherein the disrupters were absent. Most often, the change in behavior following presentation of a potential disrupter is measured as a percentage of responding relative to the baseline wherein the disrupter was absent. The rates thus normalized are transformed into logarithms so that the resulting graphical plots are linear functions (Nevin, Mandell, \& Atak, 1983). Such linear functions provide an easier interpretation of the changes in responding produced by a disrupter such that when $x=0$ responding is equal to baseline levels. Differences in resistance to change are represented as differences of the slope of the function $y$ (Tonneau, Rios, \& Cabrera, 2006). The shape of the functions generated according to this analysis may resemble exponential, linear, 
or sigmoidal functions (Nevin \& Grace, 2000). These functions are helpful in describing changes generated by disrupters and contribute to the standardization of the description of such changes.

Most studies of resistance of behavior to change use changes in response rates to index response strength, but other measures such as QL values (e.g., Elcoro, 2005) and measures of the performance during the peak trial of a PIP such as the peak rate (i.e., maximum response rate obtained during the peak trial typically reached approximately at the FI) (Grace \& Nevin, 2000) have also been used when examining the resistance of temporal control to change. The following section describes experiments conducted with disrupters, such as contextual variables and response-independent exteroceptive stimuli (e.g., lights, blackouts, food) to examine their effects on temporally controlled behavior.

\section{Contextual Variables}

Disruption of temporal control was studied in pigeons by Reynolds and Catania (1961). Keypecking under a multiple VI 3-min (signaled by an orange key) VI 3-min (signaled by a blue key) scheduled first was stabilized (access to mixed grain was used as a reinforcer). The schedule in the blue component then was changed from VI 3 min to FI 3 min for 25 sessions, after which VI responding in the orange component underwent extinction. This extinction in the orange component increased responding during the FI 3-min component relative to that which occurred during the FI component of the multiple VI 3-min FI 3-min schedule. These response rate increases were accompanied by changes in temporal patterns of responding during the FI 3min component. The latter consisted of earlier initiation of responding in the FI, resulting in a more linear pattern relative to FI responding during baseline (when extinction was not in effect).

The Reynolds and Catania (1961) findings were systematically replicated by da Silva and Lattal (2006). Pigeons responded (keypecking) on a two-component multiple schedule 
composed of a VI 60-s schedule in one component (correlated with a center red keylight, the red component) and a free-operant psychophysical procedure (FOPP) in a second component (correlated with left and right white keylights). In the FOPP two spatially different responses (e.g., left and right keylights) were available concurrently. During the first half of a trial, responding on one of the alternatives was reinforced (with access to mixed grain) according to a VI schedule and responding on the other was extinguished. During the second half of the trial, responding on the other alternative was reinforced according to a variable-interval (VI) schedule and responding to the first alternative was extinguished. One index of temporal control derived from results obtained in the FOPP is the estimated temporal threshold (ET50) or temporal point where either response is equally likely. Temporal control is indexed by how closely the ET50 coincides with the onset time of the second half of the trial (i.e., when $50 \%$ of the trial has elapsed). In da Silva and Lattal's experiment, during the first $25 \mathrm{~s}$ of the FOPP component responding was reinforced according to a VI 30-s schedule on the left key, and during the last 25 s according to the same VI 30-s schedule, but on the right key. After VI responding during the red component stabilized, responding was extinguished for 10 sessions and then the VI was reinstated in the red component for an additional 10 sessions. During extinction of responding in the red component, response rates in the FOPP component increased on the left keylight. This increase was consistent with the increased response rates obtained by Reynolds and Catania in their FI component. Extinction also increased the ET50s, reflecting more persistent responding on the left key before switching to the right key (i.e., a later switch occurred relative to the switching observed when the VI schedule was in effect in the red component). The values of the ET50 were closer to $25 \mathrm{~s}$ (the ideal time of switching, reflecting accurate temporal control) when extinction was in effect in the red component than when the VI schedule comprised that 
component. Thus, the VI schedule may be said to have disrupted temporal control and extinction may be said to have facilitated temporal control.

In sum, when extinction was in effect on one component of a two-component multiple schedule, temporal control maintained in an FI schedule in another component of that schedule was disrupted (Reynolds \& Catania, 1961). Also, in the context of two-component multiple schedules, extinction enhanced temporal control as measured by the FOPP (da Silva \& Lattal, 2006). These apparently contradicting results indicate that the effects of extinction depend on the context in which temporal control is maintained. The increased FI response rate in Reynolds and Catania, which reflected a weakening of temporal control, is consistent with the perseverative responding on the left keylight, reflecting a later switch from left to right keys relative to baseline in da Silva and Lattal.

\section{Response-Independent Exteroceptive Stimuli}

Several types of stimuli, such as ITIs programmed as blackouts (e.g., all stimuli were turned off and the emission of operant responses had no programmed consequences), short blackouts, changes in keylight color, presence or absence of a houselight, and delivery of response-independent food, have been intruded either directly or indirectly on operant responding to assess the resistance of temporal control. The procedures that involved these stimulus changes and their effects on response rates and patterns of FI responding will be described below.

Intertrial Intervals

Ferster and Skinner (1957) introduced an ITI (programmed as a blackout) after each reinforcer delivery during an FI 45-s schedule. When the duration of the ITI varied between 0 and $10 \mathrm{~min}$, response rates were inversely related to the ITI duration and response patterns also 
changed. Shorter ITI durations produced short bursts of responding after the blackout was terminated. As the ITI duration increased, so did the PRPs. Similar results were obtained when the ITIs were introduced after alternate reinforcers.

These results obtained by Ferster and Skinner (1957) can be related to those of Reynolds and Catania (1961). A short ITI after reinforcement, that is, a signaled period of nonreinforcement, increased response rates immediately after the ITI, just as Reynolds and Catania found that immediately after extinction, the PRP of the next FI was shorter and response rates during the FI were higher than those observed when the FI was preceded by a VI schedule. Thus, it could be said that the addition of an ITI after the FI reinforcer (by Ferster \& Skinner), changed the initial FI schedule into what was functionally a two-component multiple schedule composed of one FI component and one extinction component, similar to that studied by Reynolds and Catania. Both sets of results thus can be considered a positive contrast effect of extinction on FI responding.

This positive contrast effect of extinction in the multiple-schedule arrangement is similar the reinforcement-omission effect (Staddon \& Innis, 1966) observed in FI responding. The reinforcement-omission effect is an increase in response rates in FI schedules as a result of an unexpected nonreinforced FI cycle within an FI schedule. Thus, the omission of a reinforcer results in increased response rates in the following FI. This reinforcement-omission effect was observed in pigeons trained to keypeck on an FI 16-s cycles separated by 2-s ITIs (keylight off, and houselight on). When the ITI duration was increased to $12 \mathrm{~s}$ the reinforcement-omission effect was eliminated (Papini \& Hollingsworth, 1998).

Increasing the ITI duration has been considered tantamount to decreasing the overall rate of reinforcement (Bizo \& White, 1994a, 1994b). Following this idea, Bizo and White (1994a, 
1994b) used pigeons trained on a FOPP to examine whether ITI duration affected temporal discriminations (ET50s) in Experiment 1. The FOPP was similar to the one used by da Silva and Lattal (2006). More specifically, each trial of the FOPP lasted $50 \mathrm{~s}$, the first half of the trial consisted of a VI 30-s operating on the right keylight transilluminated orange and no programmed consequences operating on the left keylight (also transilluminated orange). After the first $25 \mathrm{~s}$ of the trial elapsed, keypecks on the right keylight had now no programmed consequences and only a VI 30-s was operating on the left keylight. The ITI (programmed as blackouts) durations were 10, 70, and $190 \mathrm{~s}$. In general, these authors found that as the ITI duration increased, the switch to the right keylight occurred later during the trial.

The autoshaping procedure (Brown \& Jenkins, 1968) used to train pigeons in a standard way to acquire a keypecking response also considered the effects of ITI duration. Some of the general ideas and findings from the research generated in studying the autoshaping procedure are relevant to the present experiments. For example, the fact that trial spacing enhances conditioning (Malapani \& Fairhurst, 2002), and the fact that as the ITI duration increases, the acquisition of keypecking occurs successfully with fewer reinforcers delivered (Gibbon, Baldock, Locurto, Gold, \& Terrace, 1977; Terrace, Gibbon, Farrell, \& Baldock, 1975). After compiling the literature on autoshaping, Gibbon and Balsam (1981) found that the speed of acquisition of keypecking was a function of the ratio between the ITI duration and the trial duration. In general, the longer the ITI and the shorter the trial, the fewer reinforcers were required to acquire keypecking.

In general, ITI durations along with other components of the procedure (e.g., trial duration) affect responding. Effects of parameters such as ITI durations in the area of temporal 
control are not well established. Thus, further research on the effects of ITI duration and on temporal control is necessary to clarify its role.

Changes in Houselight and Keylight Illumination

Dews (1962) attempted to disrupt FI responding to examine whether chaining was the underlying mechanism responsible for temporal control. To assess whether changes in the orderly progression of responding in FI schedules could be disrupted by houselight presentations, Dews (1962) trained pigeons on an FI 500-s schedule (correlated with a white keylight), until 11 reinforcers (i.e., access to mixed grain) were obtained. Each cycle of FI $500 \mathrm{~s}$ was separated by a 250-s ITI (blackout) and no houselight was used during this training. After 22-66 sessions on the FI 500-s ITI 250-s schedule, 50-s periods of houselight presentations were used to interrupt the responding maintained by the FI $500 \mathrm{~s}$ schedule. Each FI 500-s cycle was divided in 50-s bins (for a total of 10 bins), and the 50-s houselight periods were presented during bins 2, 4, 6, 8 and 10. During the last presentation of the houselight in each FI 500-s cycle (during bin 10), the houselight remained on until the next response was emitted and reinforced. In general, response rates in the absence of the houselight decreased, and in the presence of the houselight, response rates abruptly increased. These changes in responding yielded a step-like pattern of responding. In terms of response patterns, response frequency during the houselight-on periods increased as the time for reinforcer delivery approached. It can then be said that the positively accelerated pattern of responding was maintained, but not in the smooth manner as during the baseline. This was evidenced by cumulative records revealing "miniature FI scallops" (Dews, 1962 p. 372) within the houselight-on periods.

Dews (1962) concluded that even though the response chains were broken, the positively accelerated pattern persisted. If the underlying mechanism of temporal control is not chaining, 
how is the positively accelerated pattern maintained? To further examine this issue, other FI durations and other sequences of disruption were utilized by Dews $(1965,1966)$. Relative to his 1962 study, Dews $(1965,1966)$ examined less regular and longer blackouts using different FI values. In general, overall response rates decreased during the no-houselight presentation periods of the FIs. Dews $(1965,1966)$ also found that the closer the no-houselight period was to the time of reinforcement, the higher the response rate during the houselight presentation periods.

Dews(1966) then reversed the stimuli and used the presence of the houselight in FI training and used the absence of the houselight as the disrupter. The findings were the same as in previous experiments, responding during the absence of the houselight increased and responding during the presence of the houselight decreased. Dews's $(1962,1965,1966)$ findings suggest that FI schedules maintain organized patterns of responding over extended time periods even when stimuli are systematically intruded, according to different patterns, at various points within the FI. In sum, the integrity of temporal control remains despite the intrusion of stimuli.

Similar to Dews' 1966 study in which the temporal location of houselight/no-houselight periods within an FI schedule was varied, Farmer and Schoenfeld (1966) also examined the effects on temporal control of varying the temporal location of a 6-s green keylight intruded at different points within an FI 60-s schedule (correlated with a white keylight). When the interval between the green keylight and the reinforcer was short $(\leq 12 \mathrm{~s})$ responding was low throughout most of the interval, but increased abruptly when the green keylight was presented and then continued until a response was reinforced. As the interval between the green keylight and the reinforcer increased from 18 to $30 \mathrm{~s}$, high response rates were observed before the onset of the green keylight, falling to almost zero during the presence of the green keylight, and returning to 
high rates (comparable to those in which the disrupter was absent) until the reinforcer was delivered.

\section{Delivery of Response-Independent Food}

The use of response-independent food to disrupt temporal control is of particular interest for the present review because it was used in the present experiments. The delivery of responseindependent food increases the access to food relative to the access to food by programmed reinforcers presented during a baseline condition. The nature of this disrupter may change levels of motivation to respond to the programmed reinforcers (Shull, 2004; Ward \& Odum, 2006).

Ward and Odum (2006) trained pigeons on a three-component multiple schedule and examined effects of prefeeding, response-independent food, and extinction. In the threecomponent multiple schedule, one component was a FI 2-min schedule (center white keylight with three vertical lines). The second component was a color-matching-to-sample procedure consisting of a sample color presented for 2-s on the center key followed by the illumination of either side lit with different colors. A keypeck to the color that matched the sample was reinforced. The third component was a temporal discrimination arrangement consisting of different blackout durations (samples $<5 \mathrm{~s}$ were considered short, and those $>5 \mathrm{~s}$ were considered long) as the temporal sample for each trial. Each sample duration was selected randomly. After its presentation, the left and right keys were transilluminated by different colors, each color corresponding to either a short or a long duration. A peck to the keylight that corresponded to the sample duration was reinforced. The components were separated by a 30-s ICI during which a blackout was in effect.

For the purposes of the present review only the effects of response-independent food on the FI 2-min component will be described. The delivery of response-independent food in the ICI 
decreased overall response rates during the FI component, but effects on patterns of responding during the FI component varied unsystematically. More specifically, ICs decreased in two pigeons and did not change for the other two. Potential interaction between schedule components could have contributed to the inconsistencies obtained in temporal control maintained by the FIschedule component. Procedures that solely measure temporal control such as the PIP may be more appropriate to assess effects of response-independent food on temporal control.

Temporal control maintained in a multiple PIP was disrupted by the delivery of responseindependent food by Grace and Nevin (2000). A PIP is a variation of an FI schedule (Roberts, 1981) in which individual FIs are separated by ITIs. Occasionally a peak trial was inserted. These peak trials typically are three times longer than the FI and reinforcement does not occur at their conclusion (Meck, 2003). After repeated exposure to a PIP, responding during the peak trial increases progressively, reaching its maximum approximately at the FI value, and then decreasing after the FI value has passed. Thus, responding during the peak trial has been said to resemble a Gaussian-like curve often referred to as a peak function.

Typically peak functions based on longer-duration FIs are wider than peak functions developed with shorter-duration FIs. This is consistent with the scalar property (Gibbon, 1971, 1972) which states that variability of temporal control increases proportionally to the absolute value of the interval to be timed (Gibbon, 1977). Such variability is evidenced by wider response distributions produced with longer interval durations than with shorter interval durations (Church, 2002). Thus, it is said that temporal discriminations become less accurate as the interval to be timed increases. This finding has been confirmed repeatedly when using multiple PIP involving two durations (short and long). For example Levin et al. $(1996,1998)$ found that when human subjects are trained (the response was to press a space bar on a computer monitor, and 
visual feedback displayed on a computer screen was used as a reinforcer) on a multiple PIP based on an FI $7 \mathrm{~s}$ and an FI 17 s, wider peak functions were obtained for the longer-duration FI. Also using rats trained to press a lever (food pellets were used as reinforcers) on a multiple PIP, Drew, Fairhurst, Malapani, Horvitz, and Balsam (2003) found wider peak functions developed in the component with a PIP based on an FI 36 s (288-s peak trial) than in a component based on an FI 12 s (36-s peak trial).

Grace and Nevin (2000) trained pigeons on a two-component multiple PIP, one component based on an FI $10 \mathrm{~s}$ (30 s-peak trial) and the other based on an FI $30 \mathrm{~s}$ (90-s peak trial) (Experiment 2). The component with FI $10 \mathrm{~s}$ was richer than the FI $30 \mathrm{~s}$, thus, according to the behavioral momentum theory, the FI 10-s component was expected to be more resistant to change. Before response-independent food was delivered during the 10-s ICI, the wider peak functions were obtained with the FI 30s than with the FI 10 s. Response-independent food delivered according to a VT $7.5 \mathrm{~s}$ did not change overall response rates of both components and it increased the variability of response distributions during peak trials more for the peak trial based on FI $10 \mathrm{~s}$ than on FI $30 \mathrm{~s}$.

Using a FOPP, Lieving (2003) extended Grace and Nevin's (2000) analysis, also using a multiple schedule with pigeons. A green keylight was correlated with a VI 120-s schedule and a red one with a VI 30-s schedule. There were 15 components of each color, with each separated by a 15 -s ICI. During the first $25 \mathrm{~s}$ of each trial, the VI schedule was in effect only on the left key and during the last $25 \mathrm{~s}$ it was in effect only on the right key. The transition from left to right was unsignaled. Temporal control was increasingly disrupted as a function of the frequency of response-independent food, for example, the VT 7.5-s schedule resulted in the lowest ET50s in both VI 30 and 120-s schedules. 
Disruption of temporal control as studied by both Grace and Nevin (2000) and Lieving (2003) involved delivery of response-independent food during the ICIs. Such delivery of response-independent food thus is considered indirect because the disrupter was temporally removed from temporally controlled responding. It could also be said that there was a delay between the delivery of response-independent food and temporally controlled behavior, but such delay was not being manipulated in those previously described experiments.

An examination of the direct effects of the delivery of response-independent food on temporally controlled responding was conducted by Lattal and Bryan (1976). They examined the effects of response-independent food superimposed directly during an FI schedule. In general, the scalloped response pattern developed in the absence of response-independent food changed to more linear patterns of responding when the response-independent food was present, as reflected in both cumulative response patterns and QL values.

Extending the analysis of effects of response-independent food on temporally controlled behavior, Elcoro (2005) delivered response-independent food during either the first, a randomly selected, or the last FI preceding a peak trial (2-5 FIs preceded each peak trial). The closer the response-independent food was in time to the peak trial, the greater the disruption in temporal control during that peak trial. More specifically, QL values for the first third of the peak trial were lowest when the response-independent food was delivered during the last FI preceding a peak trial, relative to when it was located in a randomly selected FI or during the first one. Overall response rates and peak rates also decreased as a function of the location of the responseindependent food.

Elcoro 's (2005) results can be related to those of Dews $(1962,1965,1966)$ and Farmer and Schoenfeld (1966), who also examined the effects of the temporal location of intruded 
exteroceptive stimuli (keylight and houslight changes) on temporally controlled responding, albeit using different procedures. The results of all these three studies suggest that the temporal location of intruded stimuli systematically affects temporally controlled responding. In Elcoro's study, when the delivery of response-independent food was closer to the onset of the peak trial, more responding occurred early during the peak trial than when it was located further away from the onset of the peak trial. Similarly, response rates increased when the 6-s green keylight (in Farmer \& Schoenfeld), and houselight presentation (in Dews) was closer to the time of reinforcer delivery.

\section{Delay-of-Disruption Gradients}

Effects of the temporal location of a disrupter on temporal control may be described in terms of a delay-of-disruption gradient. The concept of delay-of-disruption gradients is theoretically significant because it suggests a relation between temporal control and the basic learning mechanism of temporal contiguity between events and their effects on behavior.

Delay-of-disruption gradients may be considered functionally similar to delay-ofreinforcement gradients in that increases or decreases in the time between two specific events have systematic effects on responding. More specifically, in delay-of-reinforcement gradients the effect of a reinforcer is weakened as the delay between response and reinforcer is increased. In delay-of-disruption gradients, as the delay between the response-independent food and responding on the peak trial decreases, the disruption of temporal control increases.

Elcoro's (2005) delay-of-disruption gradients were constructed using QLs and peak times separately as a function of the location of response-independent food within FIs preceding a peak trial. The manipulation conducted in the present experiments was similar to that conducted by Elcoro in the sense that response-independent food was temporally removed from the FI $150 \mathrm{~s}$ 
(Experiment 1) and the FI $30 \mathrm{~s}$ (Experiment 2). In Elcoro, response-independent food was temporally removed from the peak trial. One difference between these two studies though is that Elcoro delivered response-independent food within the FIs in which operant responding was occurring and in the present experiments, response-independent food was delivered during the ITIs in which operant behavior was not occurring.

\section{STATEMENT OF THE PROBLEM}

Procedures such as the FI schedule, the PIP, and the FOPP all generate and maintain temporal control. Temporally controlled behavior implies the organization of individual responses over an extended time frame. This in turn raises the question of whether these temporally integrated patterns of individual responses, that is, complex response units or operants (Hawkes \& Shimp, 1975) function the same as single-response operants. For example, the latter are differentially resistant to change as a function of such variables as the rate, magnitude, and delay of reinforcement, but relatively little is known about the resistance to change of temporally controlled responding. Thus, the purpose of the present experiments was to further examine the structure and cohesiveness of temporal control developed in FI schedules. In keeping with the one of the resistance-to-change tests for single-element operants (e.g., Nevin, 1974) the delivery of response-independent food served as the test of the resistance of FIcontrolled responding to change.

Using a two-component multiple PIP arrangement, Grace and Nevin (2000) found (in Experiment 2) that response-independent food delivered according a VT 7.5 s during a 10-s ICI increased variability of responding during the peak trials based on an FI 10 s more than during the peak trials based on an FI 30 s. Lieving (2003) used a different procedure to generate temporal control, the FOPP, and delivered response-independent food during the ICIs separating 
the FOPP components. Lieving found that as the frequency of response-independent food increased, temporal control was more likely disrupted.

Response-independent food delivered within the FI itself reliably disrupted temporal control by changing positively accelerated response patterns into more linear patterns (Lattal \& Bryan, 1976). Using a PIP as Grace and Nevin (2000) and response-independent food delivered within the FI intervals (as in Lattal and Bryan) preceding the peak trial, Elcoro (2005) examined effects of different temporal locations of such response-independent food on temporal control maintained on the peak trail. Specifically, response-independent food was systematically delayed from the peak trial (far from, randomly delivered, and close to). In general, as the delay between the response-independent food and the peak trial decreased, the disruption of temporal control increased.

Delay of disruption gradients are functionally similar to delay of reinforcement gradients in that increases or decreases in the time between two specific events have systematic effects on responding. The concept of delay of disruption gradients reveals a relation between temporal control and the basic learning mechanism of temporal contiguity between events and their effects on behavior. Temporal contiguity between responses is basic in understanding the development of the flow and shape of response patterns of temporally controlled behavior. By varying the delay between response-independent food and the upcoming FI interval, the general mechanism of temporal contiguity and its effects over responding were examined.

The primary goal of the present experiments was to further develop the generality of the concept of delay-of-disruption gradient by using a procedure other than the PIP to measure temporal control. Specifically, effects of response-independent food delivered early and late within ITIs separating FI schedules were investigated to examine whether the disruptive effects 
of response-independent food are a function of their temporal location as observed by Elcoro (2005).

The secondary goal was to examine the disruption of temporal control as a function of both FI value and ITI value. The fact that responding maintained by longer FI durations is more variable than responding maintained by shorter FI durations (Bizo \& White, 1994a, 1994b; Church, 2002; Gibbon, 1977; Lieving, 2003) leads to the question of whether different FI durations are differentially resistant to change. The ICI values previously employed in resistance-to-change studies have been short (e.g., 10-20 s). Additionally, as the ITI duration decreased, PRP values decreased relative to when longer ITIs were in place (Ferster \& Skinner, 1957), and when the ITI duration in a FOPP was increased, responding tended to occur later in the trials (Bizo \& White). Whether such ITI changes affect the resistance of temporal control to change will be examined in the present experiments.

\section{EXPERIMENT 1}

Several experiments have shown that responding under contingencies generating temporally controlled responding is disrupted by imposing response-independent food during an ICI or ITI that separates instances of those contingencies from one another. For example, Grace and Nevin (2000) showed that response-independent food presentations at variable times during an ITI between components of a multiple PIP disrupted temporal control. Lieving (2003) found that such disruption was a function of the rate or magnitude of the disrupter. Using a different procedure, Elcoro (2005) showed that temporal control during the peak trial of a PIP was differentially disrupted as a function of the temporal location of a disrupted FI in the sequence of FIs preceding the peak trial. The present experiment combined the delay-of-disruption gradient notion from Elcoro with the methods of Grace and Nevin and Lieving to examine the effects of 
the location of a temporal disruptor on FI responding. Because the duration of the ITI has been shown to affect FI performance (Ferster \& Skinner, 1957) it also was of interest to examine these location effects as a function of ITI duration.

\section{Method}

\section{Subjects}

Three experimentally naïve male White Carneau pigeons $(2403,772, \& 840)$ were maintained at approximately $80 \%$ of their free-feeding body weights. The pigeons were housed individually and provided with free access to water and digestive grit. Illumination (12 h light/dark cycle) and temperature $\left(24^{\circ} \mathrm{C}\right)$ in the vivarium were constant.

\section{Apparatus}

Two operant conditioning chambers were located in sound-attenuating enclosures. The work area of each chamber was $32 \mathrm{~cm}$ long by $30 \mathrm{~cm}$ high by $30 \mathrm{~cm}$ wide. An aluminum work panel comprised one wall of the chamber. One 2.54-cm diameter response key was centered on the midline of the work panel, and was transilluminated by a white light. Reinforcement was 3-s access to mixed grain from a hopper located behind a $4.5-\mathrm{cm}$ square feeder aperture centered on the aluminum panel and on the midline of the work panel $9 \mathrm{~cm}$ from the floor on one chamber, and the aperture was a 5-cm diameter for the other chamber. The hopper was raised into the aperture, which was illuminated by a white light during reinforcement. General chamber illumination was provided by a houselight located at the top of the chamber. A ventilation fan and a white noise generator masked extraneous noise. Experimental events and data were controlled and recorded with Med-Associates ${ }^{\circledR}$ programming and interfacing located in an adjacent room to that housing the chambers. 


\section{Procedure}

\section{Experimental Conditions}

The pigeons first were trained to eat mixed grain from the hopper. After that, pecking the center response key, transilluminated white, was shaped manually. After each pigeon pecked the key consistently, an FI 5-s schedule was in effect. Successive FIs were separated by a 135-s ITI during which the keylight and houselight illumination were turned off and keypecks had no programmed consequences. The value of the FI was increased by 5 s per session until a value of $150 \mathrm{~s}$ was attained, at which point the experiment proper began.

Throughout the experiment, sessions occurred daily, seven days a week at approximately the same time during the light phase of the illumination cycle. Each session started with a 10-s blackout, followed by the first FI of the session. In all conditions, each FI was followed by either a 35 s or 135 s ITI, as described above. Sessions terminated after the delivery of 10 reinforcers. When the conditions consisted of an FI 150 s ITI 135 s, sessions lasted approximately 45 min and when the ITI lasted $35 \mathrm{~s}$, sessions lasted approximately $30.5 \mathrm{~min}$.

The design of the experiment was one of alternating baseline and manipulation conditions. Each manipulation condition was in effect for 15 sessions, except as noted in Table 1. Each baseline was in effect for a minimum of 13 sessions and until responding was stable. For the first two conditions, stability was based on QL values. Because this measure was not sufficiently sensitive to the changes in response patterns, after the second condition, stability was based on overall response rates (Resp/min). Stability was assessed by averaging the last six sessions of the corresponding baseline (i.e., grand mean), then calculating the average of the first three sessions of those last six, and the average of the last three sessions of those last six (i.e., submeans). The difference between each of the submeans and the grand mean did not differ in 
more than $5 \%$ of the grand mean for stability criteria to be met. Experimental conditions were in effect for 15 sessions.

The sequence of conditions and number of sessions at each for each pigeon are shown in Table 1. In the disruption/manipulation conditions, five 3-s response-independent food deliveries, $2 \mathrm{~s}$ apart, from the same hopper that delivered FI reinforcers occurred during each ITI separating the FI schedule presentations. The entire sequence of food delivery comprised a $25-\mathrm{s}$ period. Two temporal locations of these deliveries, at the Beginning and at the End of the ITI, were examined as a function of the ITI duration

Beginning. The response-independent food deliveries described above occurred at the beginning of the ITI separating each FI. This condition was conducted in the context of two ITI durations (135 and 35 s). Hereafter, this condition will be labeled Beginning condition. When the ITI was $135 \mathrm{~s}$, the response-independent food deliveries were available after $20 \mathrm{~s}$ of the ITI. The last food presentation was followed by the remaining $90 \mathrm{~s}$ of the ITI and then the next FI commenced. When the ITI was $35 \mathrm{~s}$, this Beginning condition consisted of the 25 -s responseindependent food delivery immediately after the delivery of a reinforcer. After that, the remaining $10 \mathrm{~s}$ of the ITI elapsed and a new FI schedule presentation commenced.

End. Response-independent food deliveries as described above occurred at the end of the ITI separating each FI. This condition was conducted in the context of two ITI durations (135 and $35 \mathrm{~s}$ ). Hereafter, this condition will be labeled End condition. When the ITI lasted $135 \mathrm{~s}, 110$ s of the ITI followed the 25 -s delivery of response-independent food. The last food presentation was contiguous with the start of the next FI. When the ITI lasted 35 s, 10 s of the ITI followed the 25-s response-independent food delivery, so that the last food presentation followed the onset 
of the next FI schedule. Response-independent food deliveries (either at the Beginning or at the End of the ITI) did not alter the duration of the sessions.

Results

Table 1 shows the mean and standard deviation of overall response rates, PRPs, and reinforcement rates for the last six sessions of each condition for each pigeon. Overall response rates were calculated by dividing the total number of responses emitted during FI schedules and the time spent on the FI (excluding ITI time and reinforcement time). Mean PRPs were obtained by averaging PRPs for each FI interval. Overall reinforcement rates were calculated by dividing the total number of reinforcers delivered during a session by the time spent on the FI (excluding ITI time and reinforcement time). During all sessions no responding was observed during the ITI periods.

Systematic effects of the temporal location of response-independent food within the ITI were not observed on overall response rates. The standard deviations of the mean overall response rates for the baseline conditions preceding the delivery of response-independent food decreased progressively. The PRPs consistently increased with the End condition with both ITI durations, except for Pigeon 2403 when exposed to the End condition with 35-s ITI. Postreinforcement pauses changed inconsistently with the Beginning condition. The most systematic changes in response patterns were observed during the End condition. When the ITI duration was changed from $135 \mathrm{~s}$ to $35 \mathrm{~s}$, overall response rates increased for Pigeons 2403 and 772 and slightly decreased for Pigeon 840 . Reinforcement rates were mostly constant across conditions. 
Table 1

Experimental conditions in order of presentation (second column from left to right) and number of sessions (third column) for Experiment 1. Mean overall response rates for the first six sessions in which response-independent food was delivered (measured in Resp/min, fourth column), mean overall response rates for the last six days of all conditions (measured in Resp/min, fifth column), mean PRP (measured in s, sixth column), and average reinforcement rates (measured in Reinf/min, seventh column). Corresponding standard deviations for each mean are in parentheses.

\begin{tabular}{|c|c|c|c|c|c|c|}
\hline Pigeon & Schedule & $\begin{array}{l}\text { Number } \\
\text { of } \\
\text { sessions }\end{array}$ & $\begin{array}{c}\text { First Six } \\
\text { Sessions } \\
\text { (Resp/min) }\end{array}$ & $\begin{array}{c}\text { Last Six } \\
\text { Sessions } \\
\text { (Resp/min) }\end{array}$ & PRP (s) & Reinf/min \\
\hline \multirow[t]{10}{*}{2403} & FI $150 \mathrm{~s}$ ITI $135 \mathrm{~s}$ & 68 & & $57.12(7.32)$ & $46.97(10.66)$ & $0.40(0.00)$ \\
\hline & Beginning & 15 & $62.89(9.11)$ & 58.39 (7.39) & 31.53 (8.35) & $0.40(0.00)$ \\
\hline & FI $150 \mathrm{~s}$ ITI $135 \mathrm{~s}$ & 35 & & $69.22(7.27)$ & $37.43(14.90)$ & $0.40(0.00)$ \\
\hline & End & 15 & $48.18(9.48)$ & $49.84(6.09)$ & 44.56 (13.38) & $0.40(0.01)$ \\
\hline & FI $150 \mathrm{~s}$ ITI $135 \mathrm{~s}$ & 10 & & $47.44(6.65)$ & $29.26(10.56)$ & $0.39(0.03)$ \\
\hline & FI $150 \mathrm{~s}$ ITI $35 \mathrm{~s}$ & 13 & & $61.82(4.67)$ & $24.64(3.01)$ & $0.40(0.00)$ \\
\hline & Beginning & 15 & $82.20(11.82)$ & $62.81(5.71)$ & $42.30(4.54)$ & $0.40(0.00)$ \\
\hline & FI $150 \mathrm{~s}$ ITI $35 \mathrm{~s}$ & 28 & & $44.65(2.13)$ & $37.86(9.85)$ & $0.40(0.00)$ \\
\hline & End & 15 & 55.69 (7.88) & $62.65(4.62)$ & 31.90 (8.10) & $0.40(0.00)$ \\
\hline & FI $150 \mathrm{~s}$ ITI $35 \mathrm{~s}$ & 10 & & $57.43(8.28)$ & $35.33(8.18)$ & $0.40(0.00)$ \\
\hline \multirow[t]{2}{*}{772} & FI $150 \mathrm{~s}$ ITI $135 \mathrm{~s}$ & 56 & & $46.03(7.27)$ & $49.84(4.09)$ & $0.40(0.00)$ \\
\hline & Beginning & 15 & 47.88 (3.59) & 51.72 (7.24) & $50.69(11.60)$ & $0.40(0.00)$ \\
\hline
\end{tabular}




\begin{tabular}{|c|c|c|c|c|c|c|}
\hline Pigeon & Schedule & $\begin{array}{c}\text { Number } \\
\text { of } \\
\text { Sessions }\end{array}$ & $\begin{array}{c}\text { First Six } \\
\text { Sessions } \\
\text { (Resp/min) }\end{array}$ & $\begin{array}{c}\text { Last Six } \\
\text { Sessions } \\
\text { (Resp/min) }\end{array}$ & PRP (s) & Reinf/min \\
\hline & FI $150 \mathrm{~s}$ ITI $135 s$ & 40 & & $42.92(7.15)$ & $50.27(9.51)$ & $0.40(0.00)$ \\
\hline & End & 12 & 43.51 (13.87) & $40.71(4.88)$ & 44.50 (11.69) & $0.40(0.00)$ \\
\hline & FI $150 \mathrm{~s}$ ITI $135 s$ & 20 & & $35.47(7.46)$ & $34.23(9.53)$ & $0.40(0.00)$ \\
\hline & FI $150 \mathrm{~s}$ ITI $35 \mathrm{~s}$ & 25 & & 49.59 (5.99) & $27.86(11.30)$ & $0.40(0.00)$ \\
\hline & End & 15 & 52.77 (9.29) & $48.56(5.11)$ & $42.84(2.46)$ & $0.40(0.00)$ \\
\hline & FI $150 \mathrm{~s}$ ITI $35 s$ & 40 & & $60.90(5.66)$ & $21.52(14.51)$ & $0.40(0.00)$ \\
\hline & Beginning & 15 & 43.07 (8.31) & 52.14 (7.37) & 35.89 (10.15) & $0.40(0.00)$ \\
\hline & FI $150 \mathrm{~s}$ ITI $35 s$ & 10 & & $61.13(8.37)$ & $26.52(5.06)$ & $0.40(0.00)$ \\
\hline \multirow[t]{10}{*}{840} & FI $150 \mathrm{~s}$ ITI $135 s$ & 69 & & $59.60(7.12)$ & $45.38(10.38)$ & $0.40(0.00)$ \\
\hline & End & 15 & $65.84(8.05)$ & $60.79(9.75)$ & 50.07 (3.24) & $0.40(0.00)$ \\
\hline & FI $150 \mathrm{~s}$ ITI $135 s$ & 42 & & $64.51(4.49)$ & $29.24(5.45)$ & $0.40(0.00)$ \\
\hline & Beginning & 15 & 78.15 (9.42) & $68.21(12.35)$ & 27.22 (4.12) & $0.40(0.00)$ \\
\hline & FI $150 \mathrm{~s}$ ITI $135 s$ & 10 & & $65.94(7.28)$ & $25.20(8.13)$ & $0.40(0.00)$ \\
\hline & FI $150 \mathrm{~s}$ ITI $35 \mathrm{~s}$ & 13 & & $61.37(5.66)$ & $25.44(4.41)$ & $0.40(0.00)$ \\
\hline & Beginning & 15 & $66.31(5.02)$ & $61.36(5.31)$ & $18.68(4.36)$ & $0.40(0.00)$ \\
\hline & FI $150 \mathrm{~s}$ ITI $35 s$ & 47 & & $68.84(2.25)$ & $16.27(5.76)$ & $0.40(0.00)$ \\
\hline & End & 15 & 58.47 (11.79) & $49.54(4.24)$ & 23.56 (11.73) & $0.40(0.00)$ \\
\hline & FI $150 \mathrm{~s}$ ITI $35 \mathrm{~s}$ & 10 & & $68.50(5.40)$ & $18.20(3.60)$ & $0.40(0.00)$ \\
\hline
\end{tabular}


Figure 1 shows, for each pigeon, the overall response rates for the last six sessions of each baseline condition (with ITI 135 and 35 s) and all 15 sessions of the Beginning and End conditions. Overall response rates during the baseline conditions sometimes did not recover to previous levels after the delivery of response-independent food during the ITIs. The variability of overall response rates across sessions during the conditions in which response-independent food was delivered sometimes increased during the first few sessions (e.g., Pigeons 2403 and 840).

Figure 2 shows the log-transformed percent change from baseline based on overall response rates. This measure was calculated by averaging the last six days of the corresponding baseline (i.e., average baseline). Then each overall response rate obtained for each individual session in which response-independent food was delivered (for both Beginning and End) was divided by the corresponding average baseline and then log transformed. Differences between Beginning and End were not consistent across pigeons.

Figure 3 shows the log-transformed percent change from baseline based on average PRP. This measure was calculated as described in the paragraph above, but instead of overall response rates, average PRPs were used. In general, PRPs increased when response-independent food was delivered at the end of the ITI (except for Pigeon 2403 when ITI was 35 s). When responseindependent food was delivered at the beginning of the ITI average PRPs changed unsystematically.

Figure 4 shows the number of responses across successive 1-s periods (bins) of each FI schedule during the last session of baseline and first and last session of each condition of response-independent food delivery with two ITI durations. This analysis allows for the examination of changes on response patterns maintained on the FI 150 s produced by the delivery of response-independent food. The changes in response patterns varied across Figure 1. 

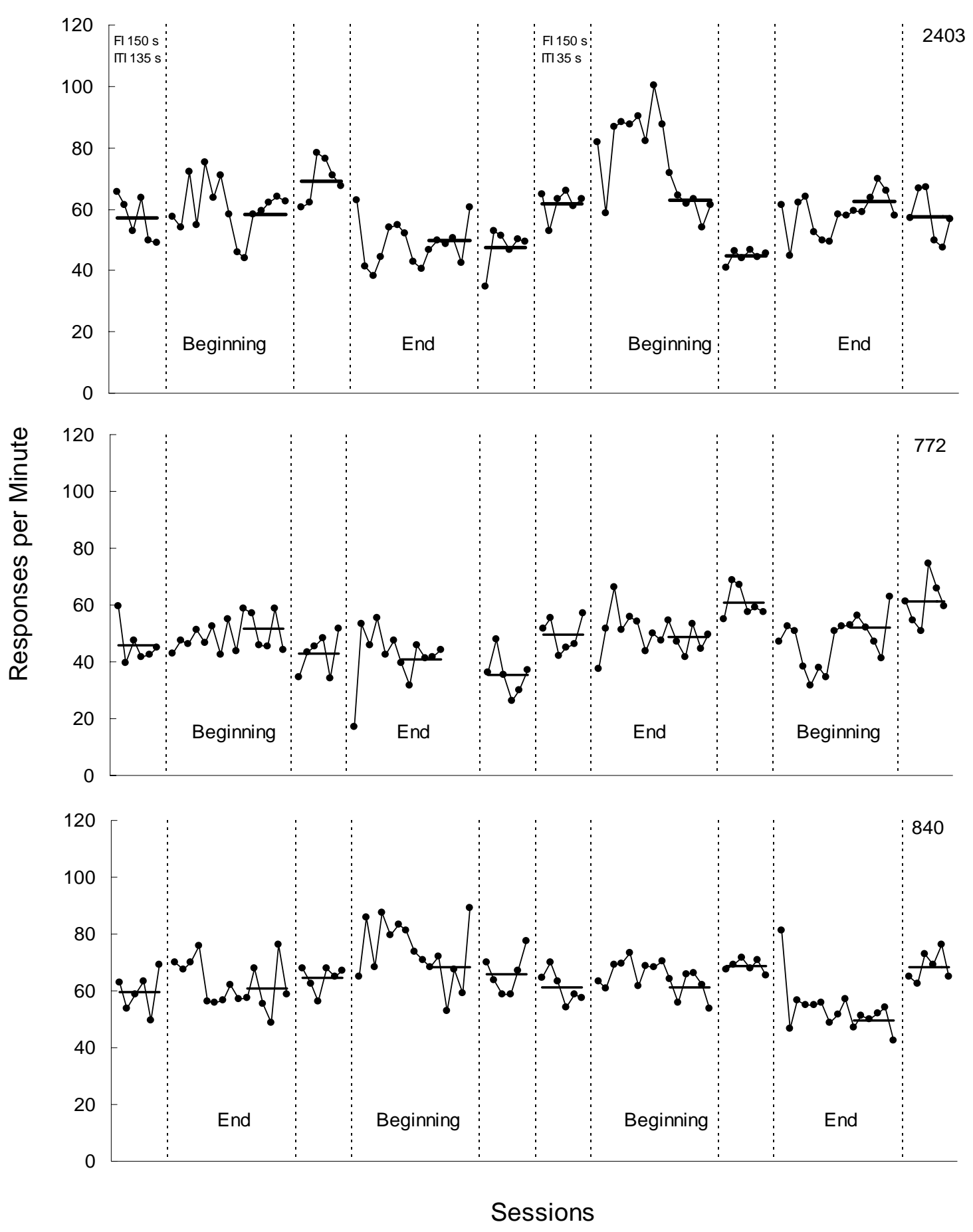

Figure 1. Overall response rates measured in response per $\min (\mathrm{Resp} / \mathrm{min})$ over the course of days for Experiment 1. The last six sessions of each baseline conditions and the 15 days of experimental conditions (Beginning and End) are shown. Solid lines superimposed to the solid circles represent the mean of the last six sessions for each condition 


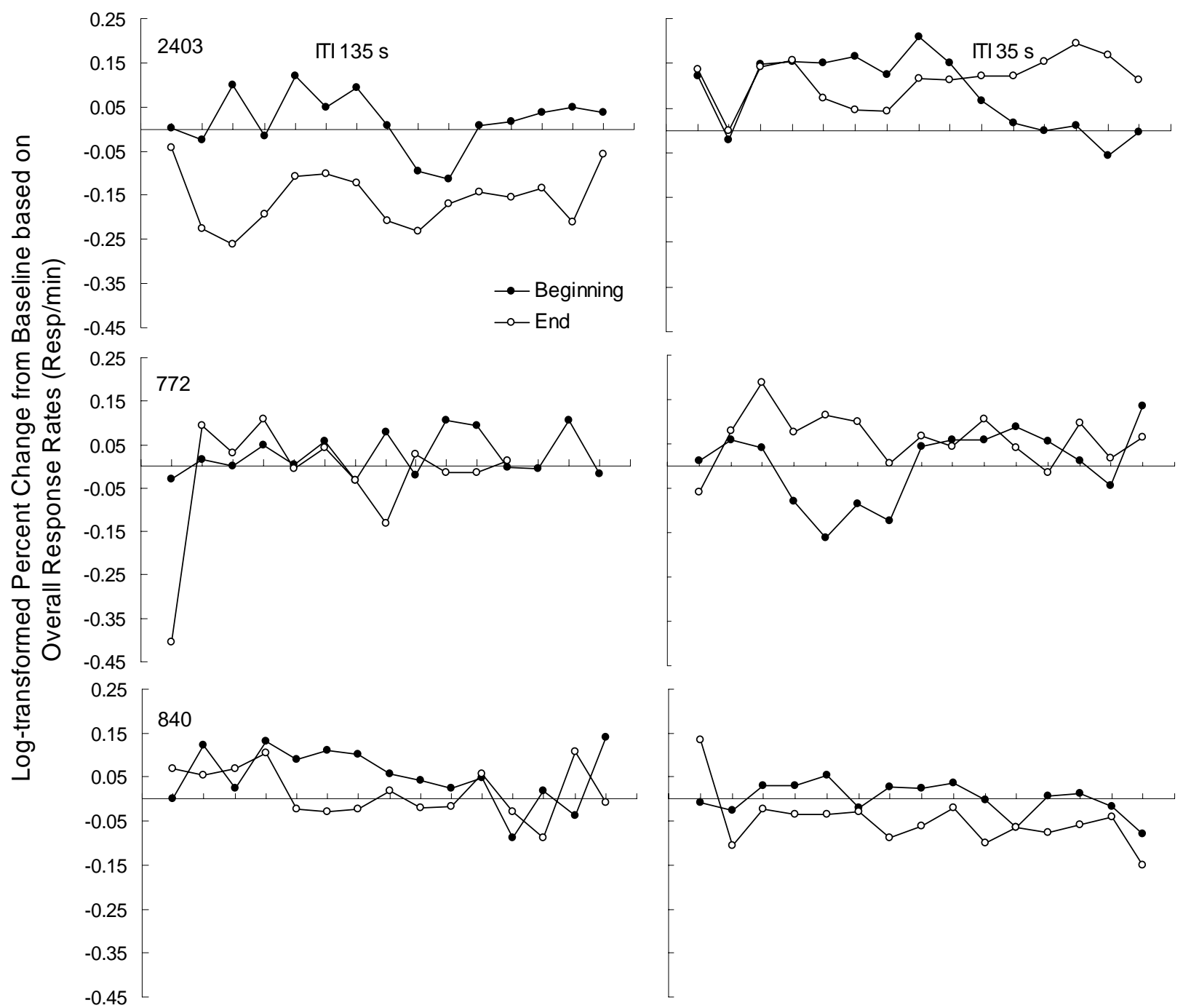

Sessions

Figure 2. Log-transformed percent change from baseline based on overall response rates (y axis) for Experiment 1. The $\mathrm{x}$ axis represents baseline responding. The filled circles represent changes obtained in the Beginning condition, and unfilled circles represent changes obtained in the End condition. If the circles are above the $\mathrm{x}$ axis, overall response rates were higher relative to the mean of the last six sessions of baseline, and if the circles are below the $\mathrm{x}$ axis, overall response rates were lower relative to baseline. Each circle represents the overall response rate for each session in which experimental condition was in effect (Beginning and End). Graphs on the left correspond to ITI $135 \mathrm{~s}$ and the graphs on the right correspond to ITI $35 \mathrm{~s}$ 


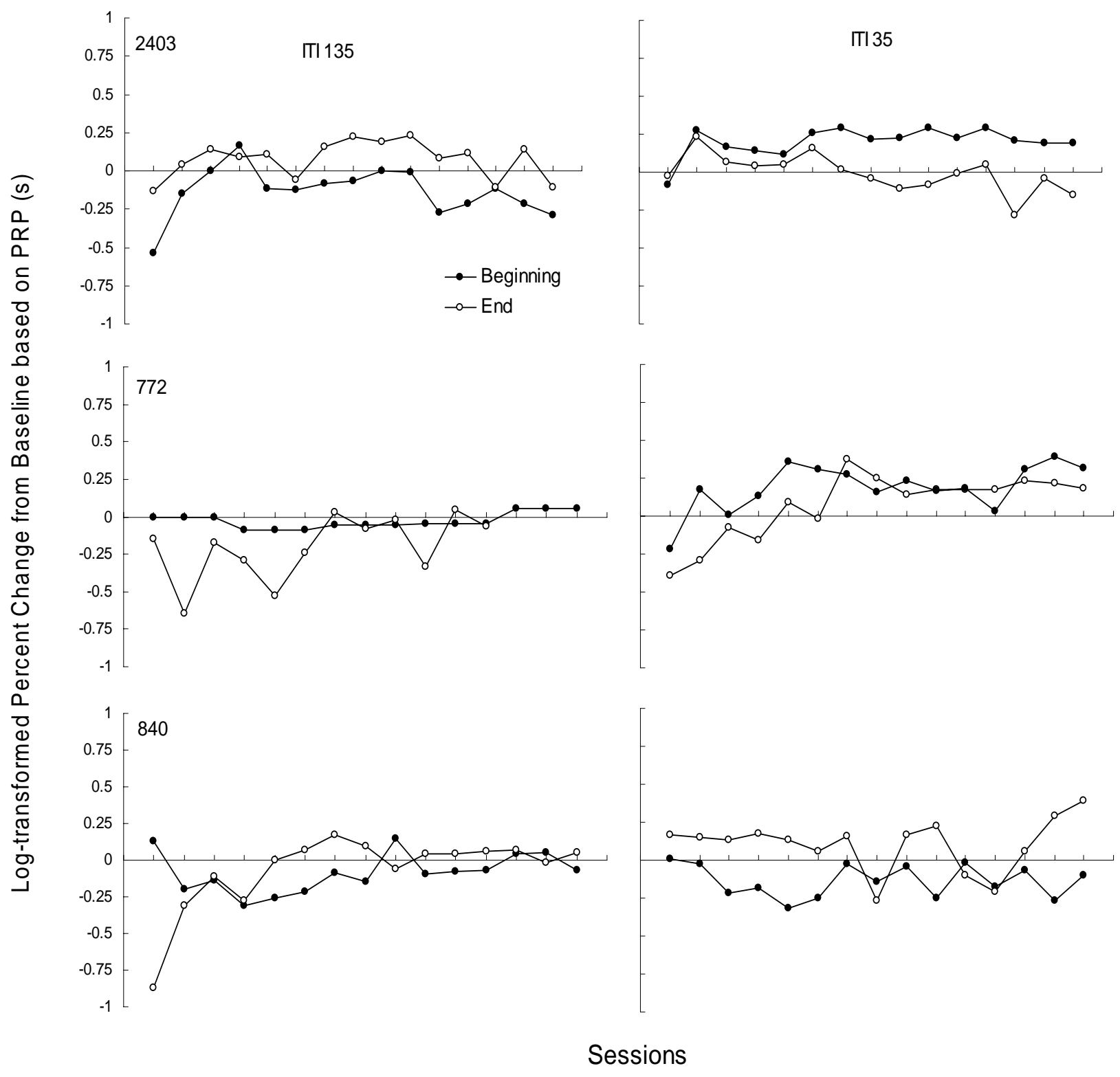

Figure 3. Log-transformed percent change from baseline based on PRPs measured in seconds (s) for Experiment 1. The $\mathrm{x}$ axis represents baseline responding. The filled circles represent changes obtained in the Beginning condition, and unfilled circles represent changes obtained in the End condition. If the circles are above the $\mathrm{x}$ axis, average PRPs were higher relative to the mean of the last six sessions of baseline, and if the circles are below the $\mathrm{x}$ axis, average PRPs were lower relative to baseline. Each circle represents the average PRP for each session in which experimental condition was in effect (Beginning and End). Graphs on the left correspond to ITI $135 \mathrm{~s}$ and the graphs in the right correspond to ITI $35 \mathrm{~s}$ 
ITI 135 s
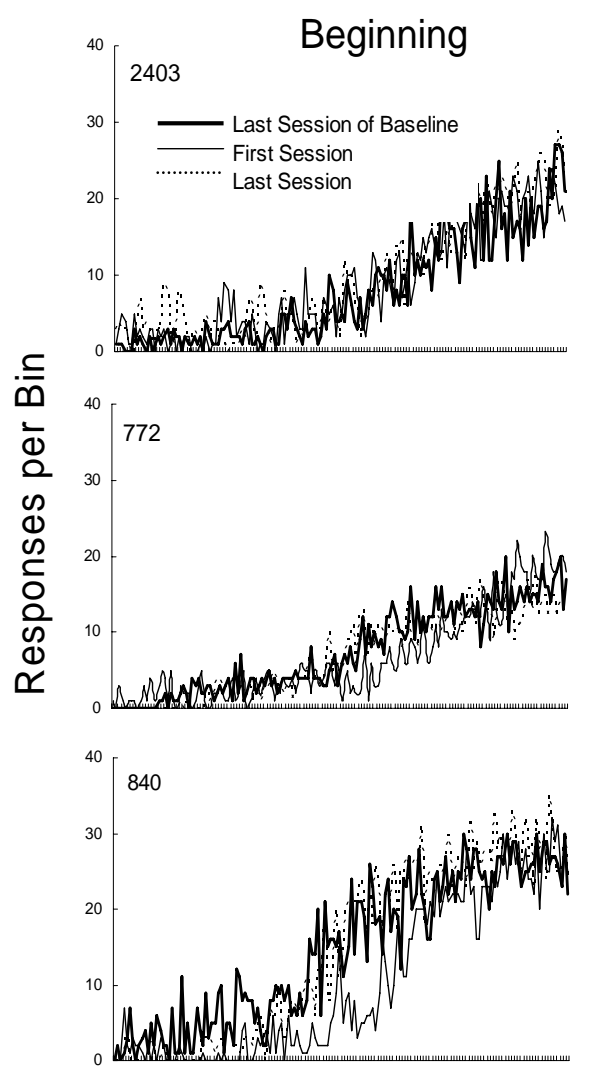
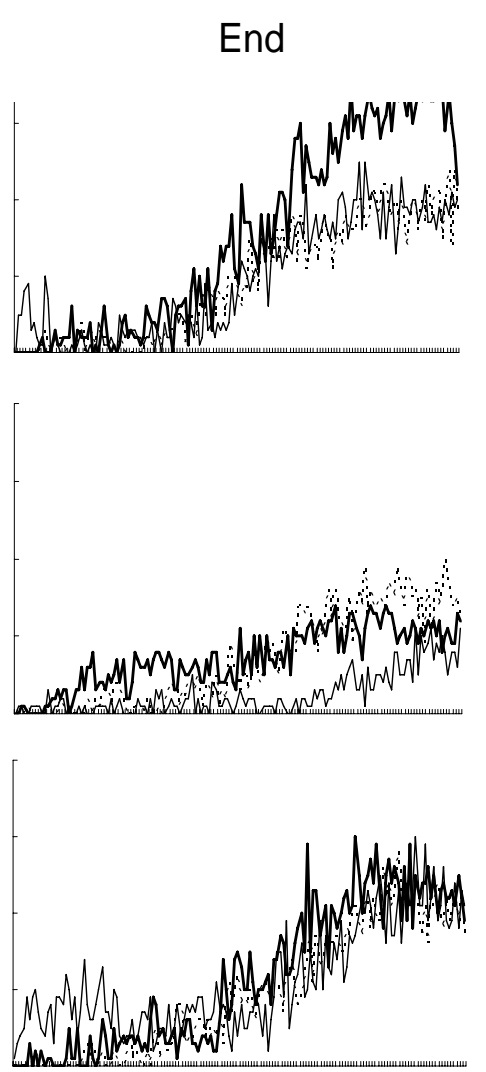

ITI $35 \mathrm{~s}$
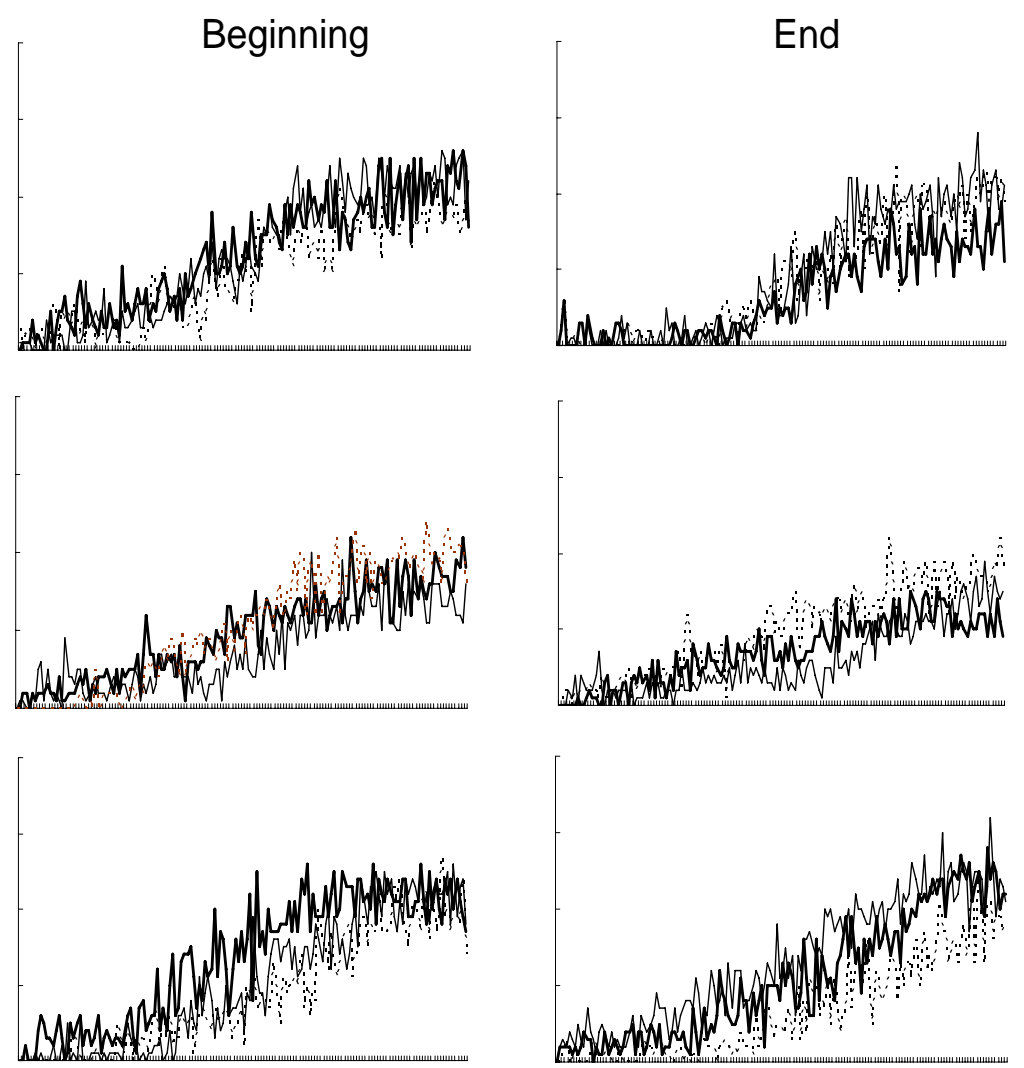

1-s Bins

Figure 4. Bin analysis for Experiment 1. The number of responses for each one-second bin is represented on the $\mathrm{y}$ axis. The $\mathrm{x}$ axis represents the interval (FI $150 \mathrm{~s}$ ) divided in 1-s bins. The functions are responses collapsed within a session. The bolded line represents responding during the last day of baseline, the thin solid black line corresponds to responding during the first day of the experimental condition and the dotted line represents responding during the last session of the experimental condition 
conditions and across pigeons. Consistent with the results described above, some of the most noticeable changes were obtained during the End condition, especially when the ITI lasted $135 \mathrm{~s}$. More specifically, responding early during the interval (see Pigeons 2403 and 840) was observed when response-independent food was delivered at the end of the 135-s ITI. Such early responding did not occur during the corresponding baseline conditions. Also, overall response rates decreased in Pigeons 2403 and 772 during the End condition with 135-s ITI.

Table 3 shows the corresponding QL values for each of the functions of the bin analysis shown in Figure 4. Three QL values were calculated for each pigeon for each condition: one for the last session of the corresponding baseline, one for the first session of the corresponding manipulation, and another one for the last session of such manipulation. In general QL values tended to decrease during the first day in which response-independent food was delivered regardless of its location within the ITI. These QL values tended to recover as the sessions progressed as evidenced by higher QL values obtained during the last day in which responseindependent food was delivered.

Table 5 shows the percent changes from baseline based on the QL values shown in Table 3. These percent changes from baseline were averaged across pigeons for each condition (first and last days of each condition separately). The variability was highest during the End conditions, especially when the ITI lasted $135 \mathrm{~s}$. In general the mean percent changes from baseline based on QL values were slightly higher during the experimental manipulations than baseline conditions. 
Table 3

Quarter-life values for each pigeon calculated for the last session of Baseline, First and Last sessions of response-independent food delivered at the Beginning and End of the ITI of Experiment 1. Pigeons were exposed to Beginning and End conditions in a different order from the one presented in the present table.

\begin{tabular}{|c|c|c|c|c|c|}
\hline \multirow{2}{*}{ Pigeon } & ITI & Condition & Baseline & First Session & Last Session \\
\hline & Duration & & & & \\
\hline \multicolumn{6}{|l|}{2403} \\
\hline & $135 \mathrm{~s}$ & Beginning & 0.63 & 0.59 & 0.61 \\
\hline & & End & 0.61 & 0.59 & 0.60 \\
\hline & $35 \mathrm{~s}$ & Beginning & 0.50 & 0.55 & 0.54 \\
\hline & & End & 0.61 & 0.64 & 0.63 \\
\hline \multicolumn{6}{|l|}{772} \\
\hline & $135 \mathrm{~s}$ & Beginning & 0.58 & 0.61 & 0.58 \\
\hline & & End & 0.45 & 0.61 & 0.64 \\
\hline & $35 \mathrm{~s}$ & Beginning & 0.51 & 0.54 & 0.57 \\
\hline & & End & 0.48 & 0.55 & 0.57 \\
\hline \multicolumn{6}{|l|}{840} \\
\hline & $135 \mathrm{~s}$ & Beginning & 0.53 & 0.67 & 0.59 \\
\hline & & End & 0.61 & 0.43 & 0.63 \\
\hline & $35 \mathrm{~s}$ & Beginning & 0.51 & 0.61 & 0.61 \\
\hline & & End & 0.56 & 0.51 & 0.63 \\
\hline
\end{tabular}


Table 5.

Percent change from baseline based on QL values for each pigeon, grouped by Experiment, for the last day of each baseline condition, the first and last sessions of each experimental condition (Beginning and End). These percent changes from baseline based on QL values are compared across experiments by averaging these percent changes across pigeons and then calculating two-tailed $t$ tests, $p$ values ( for each $t$ test are shown on the last column of the table.

\begin{tabular}{|c|c|c|c|c|c|c|c|c|c|c|c|c|c|c|c|c|}
\hline $\operatorname{Exp} 1$ & 2403 & 772 & 840 & $\begin{array}{c}M \\
\% \\
\text { Change }\end{array}$ & SD & Exp & 2 & 670 & 761 & 999 & 669 & $\begin{array}{c}M \\
\% \\
\text { Chang }\end{array}$ & $\mathrm{SD}$ & $\begin{array}{c}M \\
\operatorname{Exp1}\end{array}$ & $\begin{array}{c}M \\
\text { Exp2 }\end{array}$ & ${ }_{(p)}^{t}$ \\
\hline
\end{tabular}

\section{5-s ITI}

\section{Beginning}

First Session

Last Session End

First Session

Last Session

$\begin{array}{lllll}93.62 & 105.17 & 105.88 & 101.56 & 6.88 \\ 96.81 & 100.00 & 111.76 & 102.86 & 7.88 \\ 96.72 & 135.56 & 70.49 & 100.92 & 32.74 \\ 98.36 & 142.22 & 103.28 & 114.62 & 24.03\end{array}$

$\begin{array}{llll}118.57 & 95.00 & 74.60 & 116.28\end{array}$

91.21

16.79

101.11

$\begin{array}{llll}68.83 & 69.81 & 71.67 & 63.83\end{array}$

$\begin{array}{llll}107.79 & 113.21 & 78.33 & 121.28\end{array}$

68.53

105.15

3.35
18.72

100.92
114.62

$\begin{array}{ccc}1.56 & 91.21 & 0.33 \\ 2.86 & 101.11 & 0.88 \\ & & \\ 0.92 & 68.53 & 0.23 \\ 4.62 & 105.15 & 0.60\end{array}$

\section{5-s ITI}

\section{Beginning}

First Session

$\begin{array}{lllll}110.00 & 105.88 & 119.61 & 111.83 & 7.04\end{array}$

Last Session

$\begin{array}{lllll}108.00 & 111.76 & 119.61 & 113.12 & 5.92\end{array}$

End

First Session

$\begin{array}{lllll}104.92 & 114.58 & 91.07 & 103.52 & 11.82\end{array}$

Last Session

$\begin{array}{lllll}103.28 & 118.75 & 112.50 & 111.51 & 7.78\end{array}$

$\begin{array}{ccccccccc}54.79 & 88.33 & 78.33 & 85.11 & 76.64 & 15.15 & 111.83 & 76.64 & 0.01 \\ 100.00 & 105.00 & 71.67 & 127.66 & 101.08 & 23.01 & 113.12 & 101.08 & 0.38 \\ & & & & & & & & \\ 74.03 & 85.07 & 88.33 & 37.20 & 71.16 & 23.45 & 103.52 & 71.16 & 0.07 \\ 107.79 & 85.07 & 105.00 & 132.08 & 107.49 & 19.26 & 111.51 & 107.49 & 0.72\end{array}$




\section{Discussion}

The effects of the temporal location of response-independent food during both ITI durations were variable across pigeons. Overall response rates increased when responseindependent food was delivered at the beginning of the ITI (the exception was Pigeon 772 during the 35-s ITI). When response-independent food was delivered at the end of the ITI, overall response rates decreased consistently for Pigeon 2403 when the ITI was $135 \mathrm{~s}$ and for Pigeon 840 when the ITI was $35 \mathrm{~s}$. This same food location consistently increased the PRPs for Pigeon 2403 when the ITI was $135 \mathrm{~s}$ and for Pigeons 772 and 840 when the ITI was $35 \mathrm{~s}$.

As described above, in the present experiment overall response rates increased for the most part as a function of response-independent food delivered at the beginning of the ITI. Lattal and Bryan (1976) also found increases in response rates when response-independent food was first intruded directly in FI schedules, but this was largely due to the changes in response patterns brought about by the introduction of the response-independent food. In the present experiments, increases in overall response rates sometimes occurred during the first few sessions in which response-independent food was delivered (e.g., Pigeons 2403 in both Beginning conditions). Thereafter, these rates tended to return to the level of the preceding baseline condition.

The response patterns across the FI $150 \mathrm{~s}$ used in the present experiment were not systematically affected by the delivery of response-independent food. Rather, for the most part they were unchanged from the baseline, where they also were positively accelerated. This result is similar to the findings of Dews $(1962,1965,1966)$, who showed that the intrusion of exteroceptive stimuli in the form of houselight (on or off) presentations during responding maintained by FI schedules did not disrupt the typical FI patterns. 
The most pronounced change in response patterns, were early responding during the FI which was reflected in lower QL values for Pigeon 840 during the End condition with the 135 sITI. During the same condition, Pigeon 2403 also showed some responding during the initial portion of the FI 150-s schedule, but not as much as Pigeon 840 . These changes from positively accelerated to more linear patterns were similar to those observed by Lattal and Bryan (1976) in that there was increased responding during the initial portion of the interval as a function of the presence of response-independent food during the ITI. Unlike the pattern changes in Lattal and Bryan, however, the patterns here became more positively accelerated again after several sessions of response-independent food delivery in the ITI towards the end of the condition (reflected by higher QL values for those sessions relative to the first session in which responseindependent food was delivered).

The fact that response rates increased during the initial part of the FI $150 \mathrm{~s}$ as a function of the delivery of response-independent food at the end of the ITI parallels the increase in responding during the initial portion of the peak trial as a result of the delivery of responseindependent food during the FI preceding a peak trial found by Elcoro (2005). In the End condition of the present experiment and in Elcoro's previously described condition; responseindependent food was relatively contiguous in comparison to her other conditions where it was remote from the upcoming peak trial. It could be said that locating the response-independent food just before the onset of the FI left no chance for FI responding to recover from disruption as compared to when the disrupter occurred earlier, during the Beginning condition in the present experiment and the Initial condition in Elcoro. Because of the different effects as a function of the location of the response- independent food, these data partially support the generality of the concept of delay-of-disruption gradient. 
Pigeon 772 differed from the other two pigeons $(2403 \& 840)$ in the present experiment with respect to response patterns. These patterns during the baseline conditions for this pigeon became more positively accelerated as a function of the delivery of response-independent food at the beginning and at the end of the ITI (see Figure 4 and corresponding QL values in Table 3). This change was particularly evident during the End condition when the ITI was $135 \mathrm{~s}$; the response pattern during baseline was more linear and the exposure to response-independent food delivery increased temporal control in that it changed response patterns to more positively accelerated as the sessions in which response-independent food was delivered progressed.

In the present experiment, overall FI response rates did not change consistently as a function of the ITI duration. During the baseline conditions, shortening the ITI duration from 135 to $35 \mathrm{~s}$ increased overall response rates and decreased PRPs of two (2403 \& 840) of three pigeons. This finding is consistent with Ferster and Skinner's (1957) observations of a direct relation between PRP and ITI duration. Shortening the ITI duration while maintaining the FI value $(150 \mathrm{~s})$ constant in the present experiment has been considered an increase in reinforcement rate by Bizo and White (1994a, 1994b). These authors observed decreases in response rates as a function of lengthening the ITI duration of a FOPP. These findings follow the same inverse relation between ITI duration and response rates observed during baseline conditions in Pigeons 2403 and 840. The present results are also consistent with Killeen, Hanson, and Osborne's (1978) observation of increased response rates as a function of decreasing interfood intervals.

When response-independent food was delivered at the beginning of both ITI durations, no consistent changes in overall response rates, PRPs, or response patterns were observed. The same result obtained when response-independent food was delivered at the end of both ITI 
durations. One possibility for such inconsistencies relates to the characteristics of FI schedules (da Silva, 2001) particularly of longer-duration FI schedules, to engender variable responding (Church, 2002; Gibbon, 1977). The marked variability of response rates and response patterns during baseline conditions in the present experiment could have contributed to the lack of consistent effects of the location of response-independent food delivered during the ITIs.

Responding maintained by longer-duration FIs results in more variable responding than do shorter-duration FIs (Bizo \& White, 1994a, 1994b; Lieving, 2003). Thus, temporal control developed in longer intervals is more likely to be variable, an observation supported by the wider peak functions observed in pigeons in a PIP based on an FI 30 s schedule when compared to the results with a PIP based on an FI 10 s (Grace \& Nevin, 2000). Such findings also have been reported with human subjects trained on a multiple PIP based on an FI $17 \mathrm{~s}$ and a FI $7 \mathrm{~s}$ (Levin et al., 1996, 1998) and rats trained on a multiple PIP based on an FI $36 \mathrm{~s}$ and an FI $12 \mathrm{~s}$ (Drew et al., 2003). By replicating Experiment 1 with a shorter FI duration in Experiment 2, which presumably would reduce variability in responding, the purpose was to examine whether less variable responding results in more systematic disruption of responding and temporal control as a function of the location of response-independent food during the ITI.

\section{EXPERIMENT 2}

In Experiment 1 response patterns maintained in a FI 150 s did not change systematically as a function of the temporal location of response-independent food delivered during both ITI values. In the present experiment, responding was shortened to an FI $30 \mathrm{~s}$ to generate more consistent responding than on a FI 150 s. This was based on the scalar property of timing (Gibbon, 1977) which states that the mean and the standard deviations of temporal estimates are proportional to the interval to be timed. Put in other words, responding under shorter-duration 
FIs is less variable than responding on longer-duration FIs, correspondingly, temporal discriminations of a longer interval are more variable (Bizo \& White, 1994a, 1994b; Lieving, 2003). Further evidence for this difference has been found by Drew et al. (2003), Grace and Nevin (2000) and Levin et al. (1996, 1998). Shortening the FI duration to FI 30 s was expected to generate less variable behavior, which in turn might result in more consistent disruptions than those observed in Experiment 1. The resistance of temporal control maintained on this schedule was also examined in the context of 135-s and 35-s ITIs.

Method

Subjects

Four experimentally naïve male White Carneau pigeons $(670,761,999, \& 669)$ were maintained under the same conditions described in Experiment 1.

\section{Apparatus}

The apparatus was the same as described in Experiment 1.

\section{Procedure}

\section{Experimental Conditions}

The pigeons first were trained to eat mixed grain from the hopper. After that, pecking the center response key, transilluminated white, was shaped manually. After each pigeon pecked the key consistently, an FI 5-s schedule was in effect. Successive FIs were separated by a 135-s ITI during which the keylight and houselight illumination were extinguished and keypecks had no programmed consequences. The value of the FI was increased by $5 \mathrm{~s}$ per session until a value of $30 \mathrm{~s}$ was attained, at which point the experiment proper began.

Throughout the experiment, sessions occurred daily, seven days a week at approximately the same time during the light phase of the illumination cycle. Each session started with a $10-\mathrm{s}$ 
blackout, followed by the first FI of the session. In all conditions, each FI was followed by either a $35 \mathrm{~s}$ or $135 \mathrm{~s}$ ITI, as described above. Sessions terminated after the delivery of 10 reinforcers. When the conditions consisted of an FI 30 s ITI 135 s, sessions lasted approximately 25 min and when the ITI lasted $35 \mathrm{~s}$, sessions lasted approximately $10 \mathrm{~min}$.

The design of the experiment was one of alternating baseline and manipulation conditions. Each manipulation condition was in effect for 15 sessions. Each baseline was in effect for a minimum of 13 sessions and until responding was stable. Stability was based on overall response rates (Resp/min). Stability was assessed by averaging the last six sessions of the corresponding baseline (i.e., grand mean), then calculating the average of the first three sessions of those last six, and the average of the last three sessions of those last six (i.e., submeans). The difference between each of the submeans and the grand mean did not differ in more than $5 \%$ of the grand mean for stability criteria to be met. Experimental conditions were in effect for 15 sessions.

The sequence of conditions and number of sessions at each for each pigeon are shown in Table 2. In the disruption/manipulation conditions, five 3-s response-independent food deliveries, $2 \mathrm{~s}$ apart, from the same hopper that delivered FI reinforcers occurred during each ITI separating the FI schedule presentations. The entire sequence of food delivery comprised a $25-\mathrm{s}$ period. Two temporal locations of these deliveries, at the Beginning and at the End of the ITI, were examined as a function of the ITI duration. These manipulations were arranged as described in Experiment 1.

\section{Results}

Table 2 shows the mean and standard deviation of overall response rates, PRPs, and reinforcement rates for the last six sessions of each condition for each pigeon. These measures 
Table 2

Experimental conditions in order of presentation (second column from left to right) and number of sessions (third column) for Experiment 2. Mean overall response rates for the first six sessions in which response-independent food was delivered (measured in Resp/min, fourth column), mean overall response rates for the last six days of all conditions (measured in Resp/min, fifth column), mean PRP (measured in s, sixth column), and average reinforcement rates (measured in Reinf/min, seventh column). Corresponding standard deviations for each mean are in parentheses.

\begin{tabular}{|c|c|c|c|c|c|c|}
\hline Pigeon & Schedule & $\begin{array}{l}\text { Number } \\
\text { of } \\
\text { sessions }\end{array}$ & $\begin{array}{l}\text { First Six } \\
\text { Sessions } \\
\text { (Resp/min) }\end{array}$ & $\begin{array}{c}\text { Last Six } \\
\text { Sessions } \\
\text { (Resp/min) }\end{array}$ & PRP (s) & Reinf/min \\
\hline \multirow[t]{10}{*}{670} & FI $30 \mathrm{~s}$ ITI $135 \mathrm{~s}$ & 40 & & $58.57(7.55)$ & $15.96(1.47)$ & $1.99(0.00)$ \\
\hline & Beginning & 15 & $50.66(20.68)$ & $28.45(5.21)$ & $22.91(1.30)$ & $1.98(0.01)$ \\
\hline & FI $30 \mathrm{~s}$ ITI $135 \mathrm{~s}$ & 39 & & $9.10(1.99)$ & $22.03(1.42)$ & $1.90(0.05)$ \\
\hline & End & 15 & $29.84(10.24)$ & $28.96(3.92)$ & $22.23(1.96)$ & $1.98(0.01)$ \\
\hline & FI $30 \mathrm{~s}$ ITI $135 \mathrm{~s}$ & 10 & & $14.43(1.00)$ & $21.53(0.67)$ & $1.94(0.03)$ \\
\hline & FI $30 \mathrm{~s}$ ITI $35 s$ & 23 & & $14.29(3.03)$ & $22.03(1.73)$ & $1.97(0.01)$ \\
\hline & Beginning & 15 & 37.08 (13.21) & 30.92 (3.79) & $21.87(0.83)$ & $1.99(0.01)$ \\
\hline & FI $30 \mathrm{~s}$ ITI $35 \mathrm{~s}$ & 13 & & $23.38(2.06)$ & $19.80(1.10)$ & $1.98(0.02)$ \\
\hline & End & 15 & 36.42 (12.64) & $33.90(2.76)$ & $21.98(0.82)$ & $1.99(0.01)$ \\
\hline & FI $30 \mathrm{~s}$ ITI $35 s$ & 10 & & $18.27(4.40)$ & $21.46(1.66)$ & $1.97(0.01)$ \\
\hline
\end{tabular}




\begin{tabular}{cccccc}
\hline & & Number & First Six & Last Six & \\
of & Schedule & $\begin{array}{c}\text { Sessions } \\
\text { Sessions }\end{array}$ & $\begin{array}{c}\text { Sessions } \\
(\text { Resp/min })\end{array}$ & PRP (s) & Reinf/min
\end{tabular}

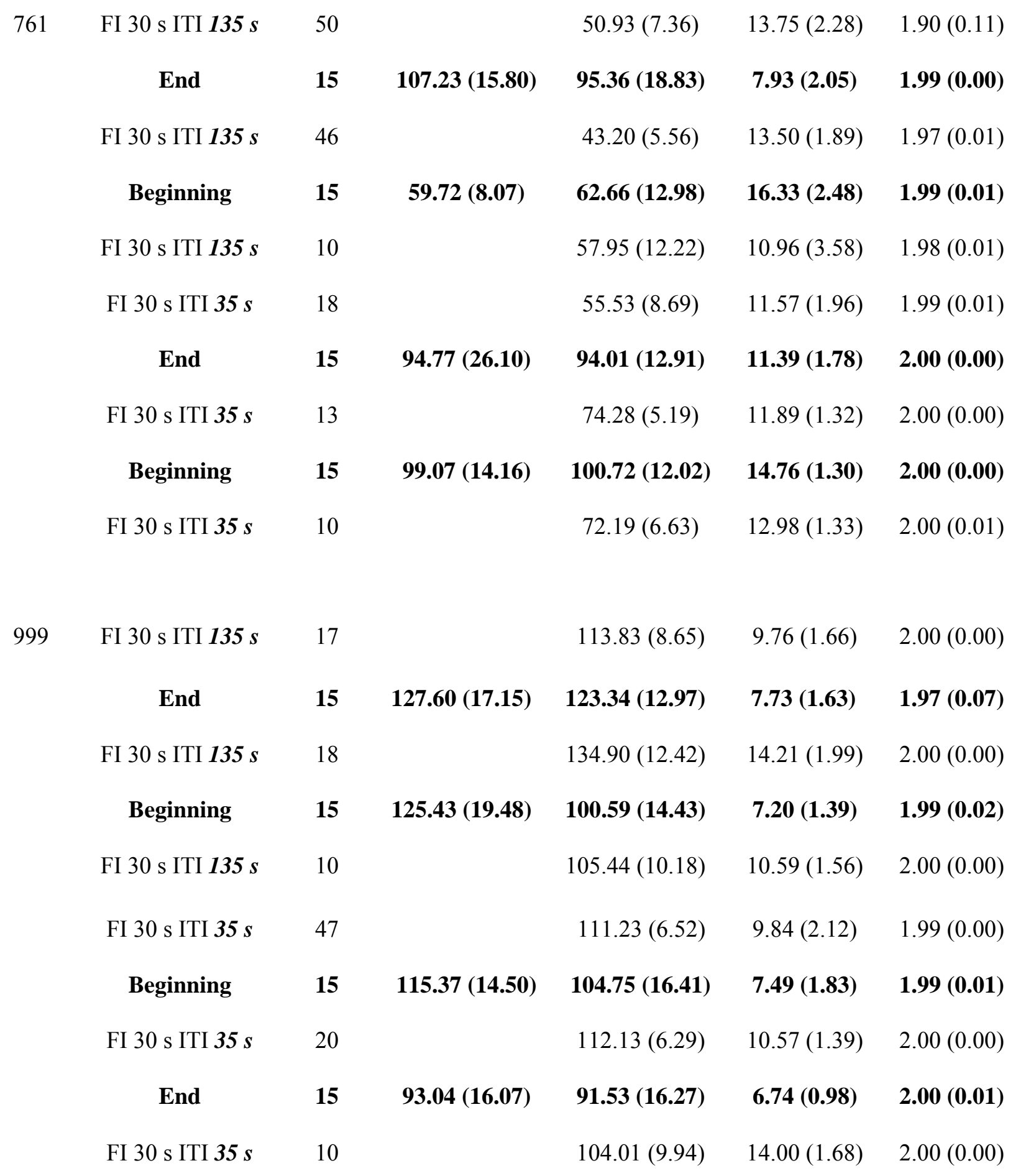




\begin{tabular}{|c|c|c|c|c|c|c|}
\hline Pigeon & Schedule & $\begin{array}{c}\text { Number } \\
\text { Of } \\
\text { Sessions }\end{array}$ & $\begin{array}{l}\text { First Six } \\
\text { Sessions } \\
\text { (Resp/min) }\end{array}$ & $\begin{array}{c}\text { Last Six } \\
\text { Sessions } \\
\text { (Resp/min) }\end{array}$ & $\operatorname{PRP}(s)$ & Reinf/min \\
\hline \multirow[t]{10}{*}{669} & FI $30 \mathrm{~s}$ ITI $135 \mathrm{~s}$ & 17 & & $125.19(5.64)$ & $6.38(0.88)$ & $1.99(0.00)$ \\
\hline & Beginning & 15 & 88.84 (31.59) & $125.03(15.94)$ & $6.85(3.47)$ & $2.00(0.00)$ \\
\hline & FI $30 \mathrm{~s}$ ITI $135 s$ & 35 & & $158.93(5.84)$ & $5.95(0.80)$ & $2.00(0.00)$ \\
\hline & End & 15 & $134.25(28.51)$ & 93.67 (10.34) & $9.97(1.15)$ & $1.92(0.10)$ \\
\hline & FI $30 \mathrm{~s}$ ITI $135 \mathrm{~s}$ & 10 & & $143.23(13.54)$ & $6.89(1.29)$ & $2.00(0.00)$ \\
\hline & FI $30 \mathrm{~s}$ ITI $35 \mathrm{~s}$ & 18 & & $119.50(8.14)$ & $7.10(0.77)$ & $2.00(0.00)$ \\
\hline & End & 15 & $101.94(30.15)$ & 46.69 (14.58) & $9.87(3.48)$ & $1.57(0.55)$ \\
\hline & FI $30 \mathrm{~s}$ ITI $35 \mathrm{~s}$ & 20 & & $116.00(9.98)$ & $6.48(1.81)$ & $2.00(0.00)$ \\
\hline & Beginning & 15 & $90.89(21.96)$ & 74.21 (3.50) & $5.60(1.55)$ & $2.00(0.01)$ \\
\hline & FI $30 \mathrm{~s}$ ITI $35 \mathrm{~s}$ & 10 & & $105.92(12.10)$ & $9.75(1.74)$ & $2.00(0.00)$ \\
\hline
\end{tabular}


were calculated as in Experiment 1. During all sessions no responding was observed during the ITI periods.

Systematic effects of the temporal location of response-independent food within the ITI were not observed on overall response rates, PRPs, or reinforcement rates. For both Pigeons 670 and 761 overall response rates increased when response-independent food was delivered, regardless of its location. The same was observed for Pigeon 999 during the End condition and ITI 135 s. During the remaining conditions, overall response rates decreased for Pigeon 999 and for all the conditions for Pigeon 669. Overall reinforcement rates slightly decreased during baseline conditions for Pigeon 670 and during response-independent-food conditions for Pigeon 669.

Figure 5 shows the overall response rates of the last six sessions of each baseline condition and the 15 sessions of the Beginning and End conditions for each pigeon. Overall response rates during the baseline conditions sometimes did not recover to previous levels after the delivery of response-independent food. Overall response rates increased during the first few sessions in which response-independent food was delivered at both ITI locations. This increase followed a decrease in the overall response rates of Pigeon 670 during the Beginning condition with 135-s ITI, of Pigeon 999 during the Beginning condition with 35-s ITI and both End conditions of Pigeon 669. The increase in overall response rates continued for Pigeon 670 throughout the End condition with the 135-s ITI and the Beginning condition with 35-s ITI, and for Pigeon 761 in all conditions (except for sessions 7 and 12 during the Beginning condition with 135-s ITI).

Figure 6 shows the log-transformed percent change from baseline based on overall response rates. This measure was calculated as in Experiment 1. For Pigeons 670, 761, and 999, 


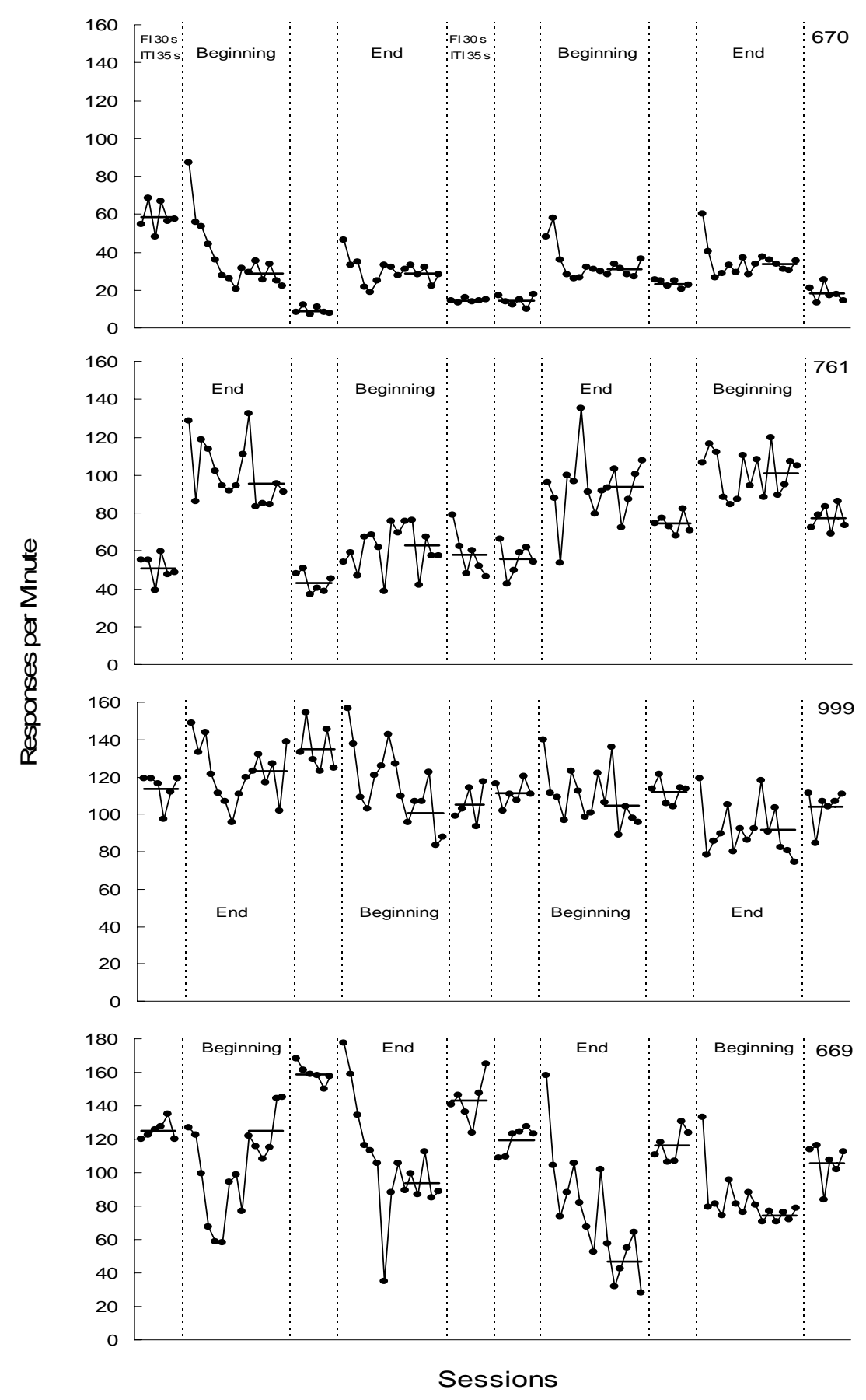

Figure 5. Overall response rates measured in responses per minute (Resp/min) over the course of days for Experiment 2. The last six sessions of each baseline conditions and the 15 days of experimental conditions (Beginning and End) are shown. Solid lines superimposed to the solid circles represent the mean of the last six sessions for each condition. Note: the y axis was scaled differently for Pigeon 669 


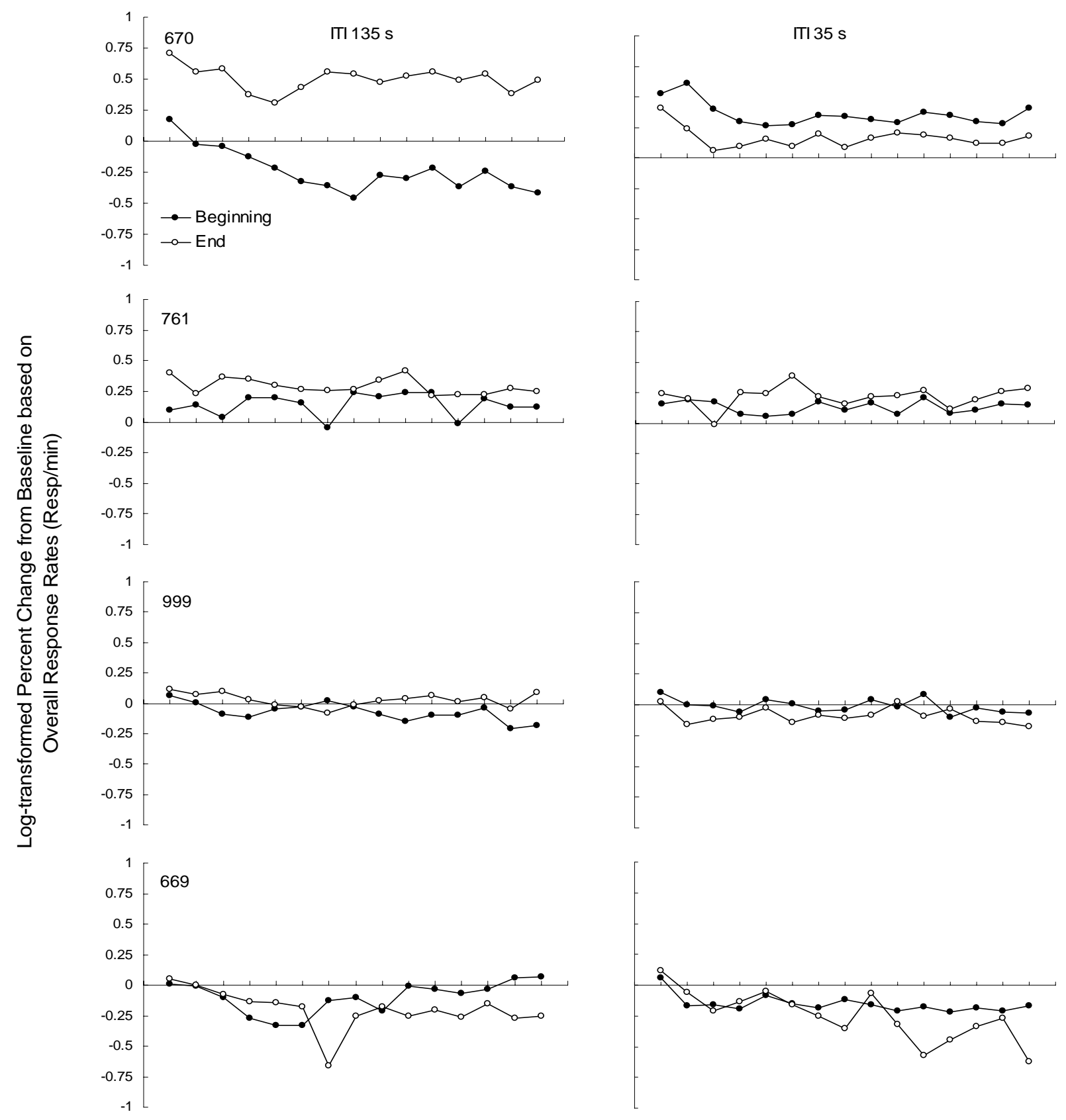

Sessions

Figure 6. Log-transformed percent change from baseline based on overall response rates (y axis) for Experiment 2. The $\mathrm{x}$ axis represents baseline responding. The filled circles represent changes obtained in the Beginning condition, and unfilled circles represent changes obtained in the End condition. If the circles are above the $\mathrm{x}$ axis, overall response rates were higher relative to the mean of the last six sessions of baseline, and if the circles are below the $\mathrm{x}$ axis, overall response rates were lower relative to baseline. Each circle represents the overall response rate for each session in which experimental condition was in effect (Beginning and End). The graphs in the left correspond to ITI $135 \mathrm{~s}$ and the graphs in the right correspond to ITI $35 \mathrm{~s}$ 
when the ITI lasted $135 \mathrm{~s}$ response-independent food delivered at the beginning reduced overall response rates more than when it was delivered at the end. Overall response rates increased substantially, relative to baseline levels, during the Beginning condition when the ITI lasted $35 \mathrm{~s}$ in Pigeons 670 and 999. During the End condition overall response rates decreased when the ITI lasted $135 \mathrm{~s}$ for Pigeon 669 and when the ITI lasted 35 s for Pigeons 999 and 669.

Figure 7 shows the log-transformed percent change from baseline based on average PRPs. This measure was calculated as in Experiment 1. During the Beginning condition, when the ITI lasted 135 s, average PRPs increased for Pigeons 670 and 761, decreased for Pigeon 999 and did not produce consistent changes for Pigeon 669. During the End condition with 135-s ITI, average PRPs decreased during the first few sessions for Pigeon 670, decreased for Pigeon 761, produced inconsistent changes for Pigeon 999, decreased during the first five sessions and then increased for the remaining sessions for Pigeon 669. During the Beginning condition with 35-s ITI average PRPs decreased for the first four sessions for Pigeon 670, decreased consistently for Pigeon 999 and decreased for the first seven sessions and then increased for the remaining eight sessions for Pigeon 669.

Figure 8 shows the number of responses across successive 1-s periods (bins) of each FI schedule as calculated in Experiment 1. When response-independent food was delivered at the end of the $135 \mathrm{~s}-\mathrm{ITI}$, responding increased during the first portion of the FI $30 \mathrm{~s}$ in all four pigeons. Such initial responding did not occur during each corresponding baseline condition. Response patterns were more pronouncedly changed as a result of response-independent food delivery at the end of than at the beginning of the ITI. During the End condition response patterns changed from positively accelerated to more linear along the FI interval. Even though during the Beginning condition there was a slight increase in responding during the first few 

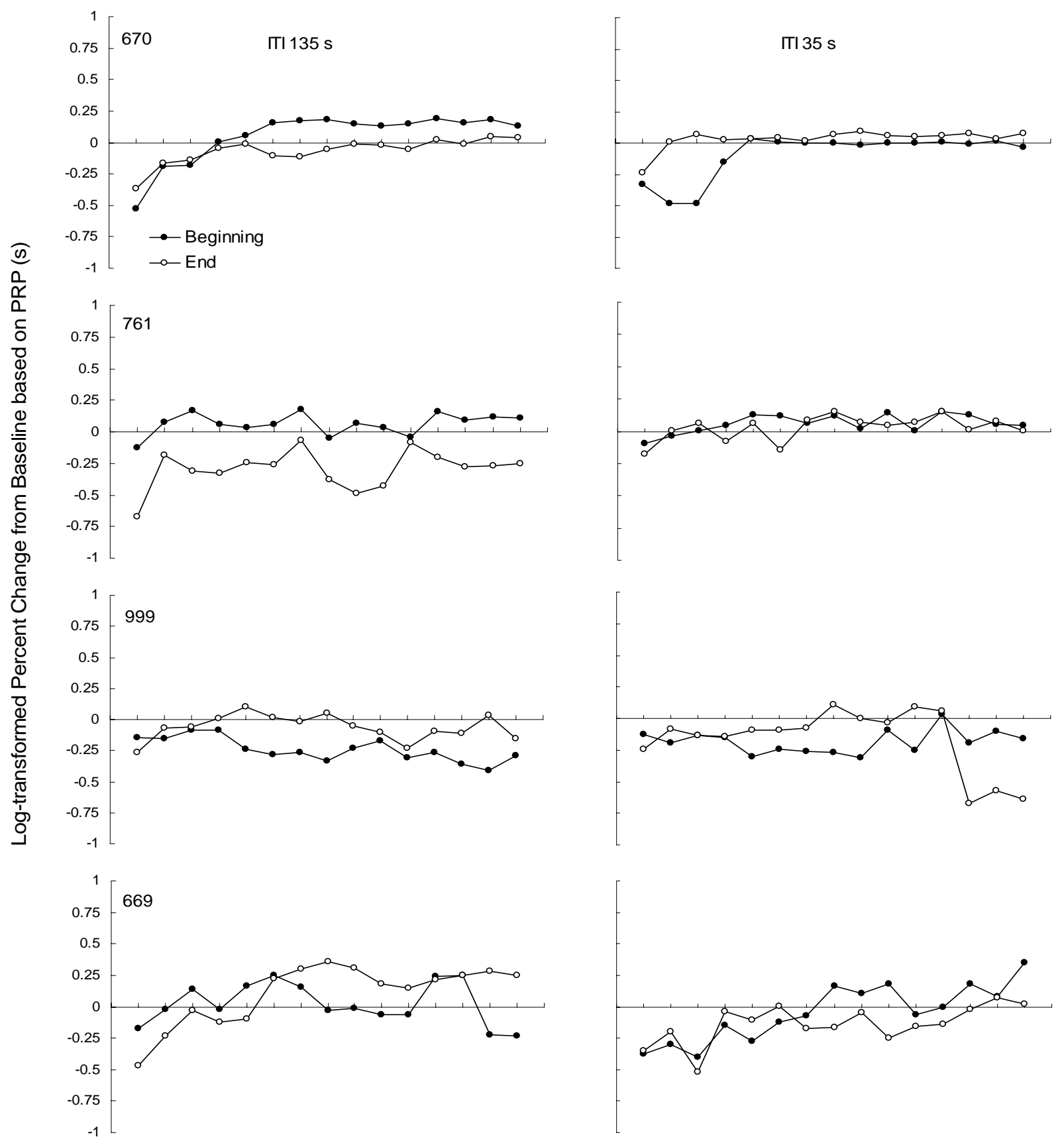

Sessions

Figure7. Log-transformed percent change from baseline based on PRPs measured in seconds (s) for Experiment 2. The $\mathrm{x}$ axis represents baseline responding. The filled circles represent changes obtained in the Beginning condition, and unfilled circles represent changes obtained in the End condition. If the circles are above the $\mathrm{x}$ axis, average PRPs were higher relative to the mean of the last six sessions of baseline, and if the circles are below the $\mathrm{x}$ axis, average PRPs were lower relative to baseline. Each circle represents the average PRP for each session in which experimental condition was in effect (Beginning and End). Graphs on the left correspond to ITI $135 \mathrm{~s}$ and the graphs in the right correspond to ITI $35 \mathrm{~s}$ 


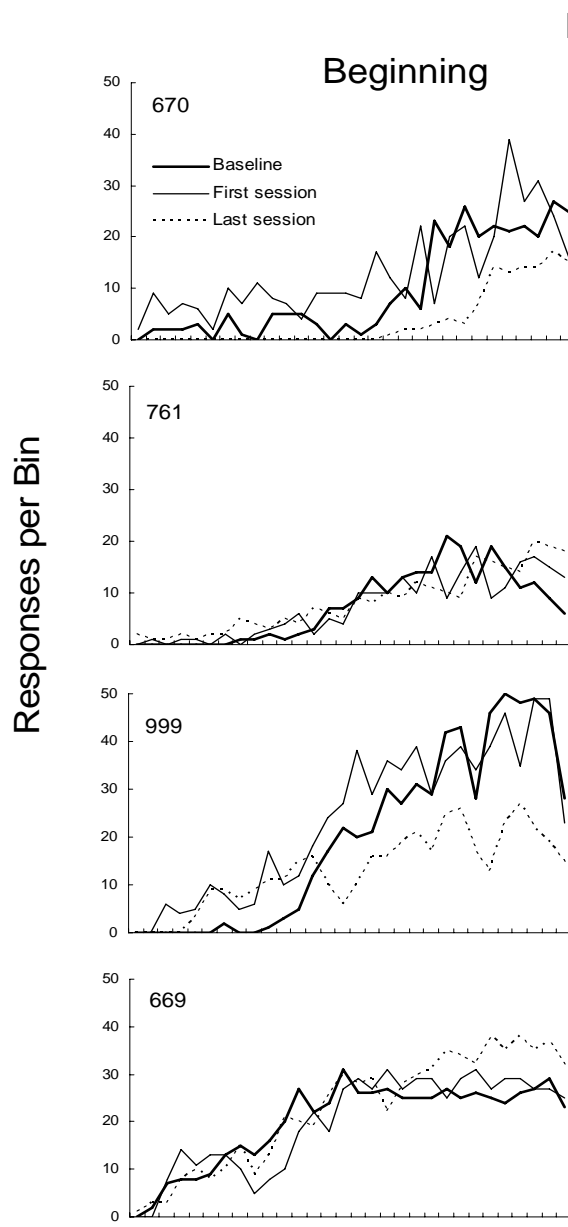

ITI 135 s
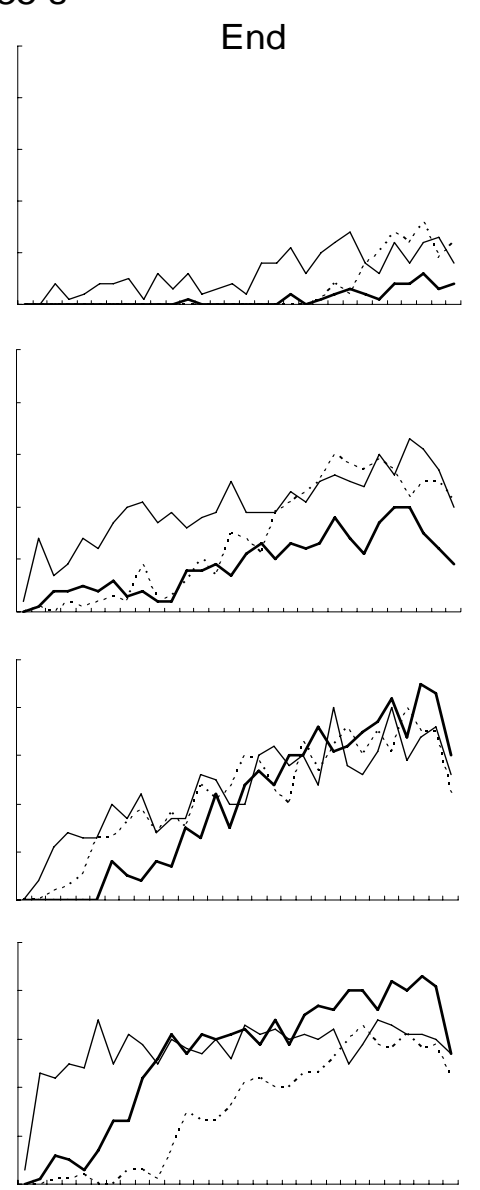

ITI $35 \mathrm{~s}$
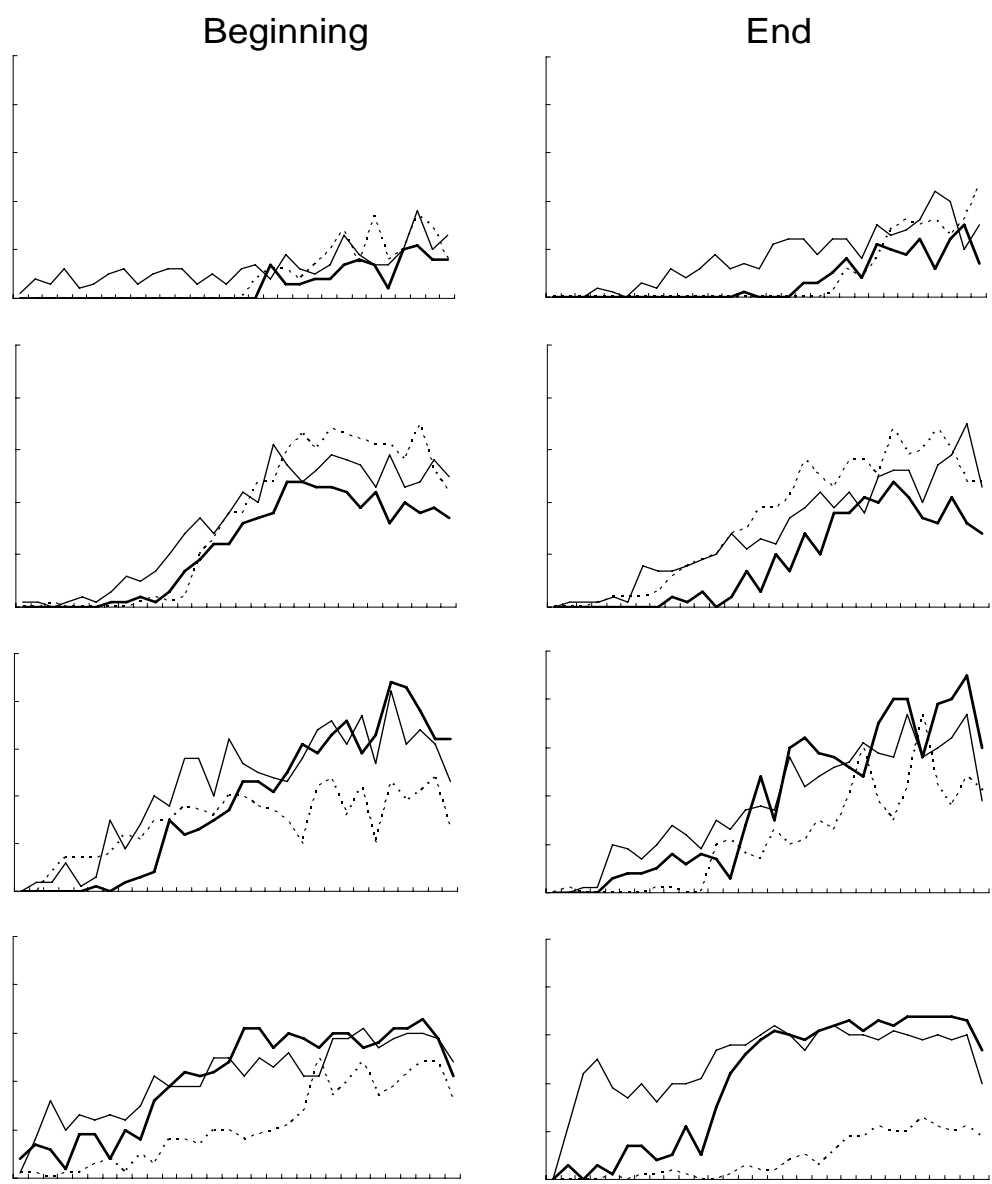

1-s Bins

Figure 8. Bin analysis for Experiment 2. The number of responses for each one-second bin is represented on the $\mathrm{y}$ axis. The $\mathrm{x}$ axis represents the interval (FI $30 \mathrm{~s}$ ) divided in 1-s bins. The functions are responses collapsed within a session. The bolded line represents responding during the last day of baseline, the thin solid black line corresponds to responding during the first day of the experimental condition and the dotted line represents responding during the last session of the experimental condition 
seconds of the interval (e.g., Pigeons 670 and 999) response patterns remained positively accelerated.

Table 4 shows the corresponding QL values for each of the functions of the bin analysis shown in Figure 8. Three QL values were calculated for each pigeon for each condition: one for the last session of the corresponding baseline, one for the first session of the corresponding manipulation, and another one for the last session of such manipulation. In general QL values tended to decrease during the first day in which response-independent food was delivered regardless of its location within the ITI. These QL values tended to recover as the sessions progressed as evidenced by higher QL values obtained during the last day in which responseindependent food was delivered. In some cases these QL values calculated for the last day were even higher than the values obtained for the corresponding baseline.

Table 5 shows the percent changes from baseline based on the QL values shown in Table 4. These percent changes from baseline were averaged across pigeons for each condition (first and last days of each condition separately). In general the mean percent changes from baseline based on QL values decreased during the first day in which response-independent food was delivered. These values tended to recover to baseline levels by the last day in which responseindependent food was delivered. 
Table 4

Quarter-life values for each pigeon calculated for the last session of Baseline, First and Last sessions of response-independent food delivered at the Beginning and End of the ITI of Experiment 2. Pigeons were exposed to Beginning and End conditions in a different order from the one presented in the present table.

\begin{tabular}{|c|c|c|c|c|c|}
\hline \multirow{2}{*}{ Pigeon } & ITI & Condition & Baseline & First Session & Last Session \\
\hline & \multicolumn{5}{|c|}{ Duration } \\
\hline \multirow[t]{4}{*}{670} & $135 \mathrm{~s}$ & Beginning & 0.70 & 0.50 & 0.83 \\
\hline & & End & 0.77 & 0.53 & 0.83 \\
\hline & $35 \mathrm{~s}$ & Beginning & 0.73 & 0.40 & 0.73 \\
\hline & & End & 0.77 & 0.57 & 0.83 \\
\hline \multicolumn{6}{|l|}{761} \\
\hline & \multirow[t]{2}{*}{$135 \mathrm{~s}$} & Beginning & 0.60 & 0.60 & 0.57 \\
\hline & & End & 0.53 & 0.37 & 0.60 \\
\hline & \multirow[t]{2}{*}{$35 \mathrm{~s}$} & Beginning & 0.60 & 0.53 & 0.63 \\
\hline & & End & 0.67 & 0.57 & 0.57 \\
\hline
\end{tabular}




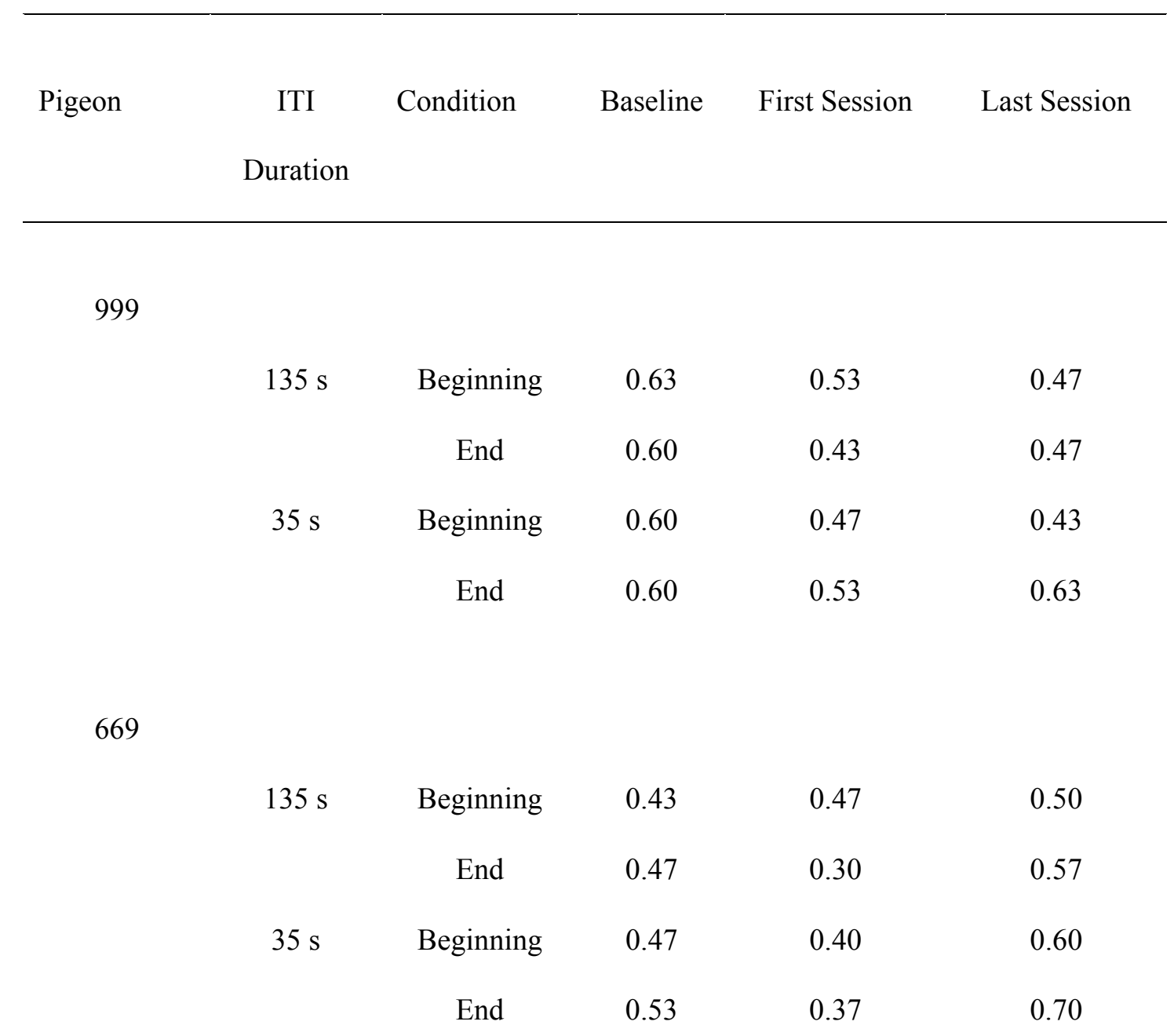




\section{Discussion}

The most systematic finding was increased responding during the first portion of the FI $30 \mathrm{~s}$ as a function of response-independent food delivered at the beginning and at the end of the 35 and 135-s ITIs (except for Pigeon 761 during the Beginning condition with 135-s ITI). These increases in responding during the first portion of the FI $30 \mathrm{~s}$ were more consistent and pronounced in the present experiment than were those when an FI 150-s schedule was in effect in Experiment 1. Although the comparison is across, rather than within, individual subjects, the results of the two experiments together suggest that temporally controlled responding maintained by an FI 30 s schedule may be more sensitive to disruption by response-independent food deliveries than responding maintained by an FI 150-s schedule.

As in Experiment 1, in the present experiment overall response rates sometimes increased when response-independent food was delivered during the ITIs. These increases occurred consistently in Pigeon 670 (except in the Beginning condition with 135-s ITI) and Pigeon 761. Contradistinctly, both Pigeons 999 and 669 decreased overall response rates as a function of response-independent food delivery regardless of its temporal location. Pigeons 670 and 761 had lower overall response rates during baseline conditions than Pigeons 999 and 669. This difference possibly suggests that the effect of response-independent food was modulated by the baseline overall response rates. These findings are consistent with earlier observations that higher response rates (i.e., those of Pigeons $999 \&$ 669) are less resistant to change than lower response rates (Lattal, 1989; Nevin, 1974).

The removal of response-independent food delivery sometimes resulted in a recovery of baseline levels of overall response rates. Such recovery of overall response rates is consistent 
with the positive contrast effect observed when extinction replaces a food schedule in one component of a two-component multiple schedule (e.g., da Silva \& Lattal, 2006; Reynolds \& Catania, 1961). In these latter studies, removing food from one of the components of a multiple schedule increased responding during the other component comprised of an FI schedule. In the present experiment, when response-independent food was removed from the ITI, which could be considered a component of a multiple schedule, responding during the FI component increased for Pigeons 670 and 761, but not for Pigeons 999 and 669.

In the present experiment response patterns were changed from positively accelerated to more linear patterns as a function of both temporal locations of response-independent food. Such change was reflected by increased responding during the initial portion of the FI $30 \mathrm{~s}$ observed with both response-independent food locations, although the greatest increases occurred during the End condition. These changes were similar to those observed by Lattal and Bryan (1976) when response-independent food was intruded during, rather than between (as was the case here), individual FIs. The fact that the patterns changed the most (as confirmed by lower QL values than in Experiment 1 for the first session in which response-independent food was delivered, see Tables $3 \& 4$ ) when the response-independent food was delivered at the end of the ITI is also consistent with the results obtained by Elcoro (2005) during peak trials as a function of delivering response-independent food during the FI that immediately preceded a peak trial. Response patterns in the present experiment recovered to their original positively accelerated patterns as the sessions in which response-independent food delivery progressed. By contrast, in the study by Lattal and Bryan (1976) linear response patterns continued as long as the response-independent food was delivered. Recovery of response patterns to positively accelerated ones also observed in Experiment 1 and is likely because the response-independent 
food delivery in the present experiments occurred during the ITI and thus was delayed from the FI onset, rather than during the FI itself as in Lattal and Bryan. The difference in respect to recovery between the present experiments and Lattal and Bryan's may suggest that direct disruption of operant responding might have longer-lasting effects than delayed disruption.

During the baseline conditions of the present experiment, shortening the ITI duration from 135 to $35 \mathrm{~s}$ did not systematically affect overall response rates or PRPs. When the ITI was shortened, only Pigeon 999 showed a slight increase in overall response rates and a decrease in PRPs. This was different from some of the results obtained in Experiment 1, where more pigeons increased overall response rate as a function of shortening the ITI. The slight increase shown by Pigeon 999 is consistent with the increase in response rates as function of decreasing interfood intervals observed by Killeen et al. (1978). These findings support the conclusion that despite the evidence that shows increased PRPs in FI schedules (Ferster \& Skinner, 1957), later switches to the operative key in a FOPP (Bizo \& White, 1994a, 1994b) and increased speed of acquisition of keypecking with an autoshaping procedure (Gibbon et al., 1977; Terrace et al., 1975) as the ITI duration increases; the ITI duration in the present experiment did not affect overall response rates or PRPs systematically nor did it increased the consistency of the changes in response patterns as a function of the temporal location of response-independent food.

Changing the FI duration from $150 \mathrm{~s}$ used in Experiment 1 to $30 \mathrm{~s}$ in the present experiment seemed to have increased the sensitivity (i.e., more pronounced deviations from baseline) of temporal control to the disruptive effects of response-independent food, given that these effects were more evident in Experiment 2 and particularly more pronounced during the End than the Beginning condition as described earlier. Such a difference in sensitivity could be related to the fact that response patterns that preceded the delivery of response-independent food 
were more positively accelerated in Experiment $2(M=0.61, S D=0.10)$ than in Experiment 1 $(M=0.55, S D=0.06)$. This difference in QL values between the two experiments was consistent with Grace and Nevin's (2000) findings of wider peak functions based of longer as than shorter FIs. These QL differences also are consistent with the scalar property of timing (Gibbon, 1977) which states that temporal control with shorter-duration FIs is more accurate than temporal control developed with longer-duration FIs. The fact that FI 30-s responding yielded higher QL values (for the baseline session preceding the first delivery of response-independent food) and was more sensitive to change than FI 150-s responding may suggest that more accurate temporal control is less resistant to change.

The decreased variability of responding for the FI $30 \mathrm{~s}$ during baseline conditions could be related to the fact that there was less time left to respond during the interval after the first response (26-80\% of the FI, or $8-24$ s) than in the FI 150 s (66 - 89\% or $100-134$ s). This restriction involves a shorter delay to reinforcement in the FI $30 \mathrm{~s}$ which may have increased the consistency of positively accelerated response patterns relative to the FI $150 \mathrm{~s}$ in which the delay to reinforcement after the emission of the first response was longer (Dews, 1970; Wearden \& Lejeune, 2006).

As noted earlier, the previous comparison between FI durations is between subjects and should be confirmed with a within-subject comparison. Grace and Nevin (2000) found that response-independent food delivered according to a VT $7.5 \mathrm{~s}$ schedule during the 10 -s ICI of a two-component multiple PIP (one component based on an FI $30 \mathrm{~s}$ and the other on an FI $10 \mathrm{~s}$ ) increased more the median and the variability of response distributions in the peak trial based on an FI $10 \mathrm{~s}$ than more than on the response distributions of the peak trial based on an FI $30 \mathrm{~s}$. Even though the dependent measures used by Grace and Nevin to measure resistance to change 
were different from the ones used in the present experiments, their results are somewhat consistent with the present results in the sense that they show greater changes relative to baseline performance in responding developed with shorter than with longer FI durations when responseindependent food was used to test the resistance of temporal control.

\section{GENERAL DISCUSSION}

Some of the findings from the present experiments extend the generality of the concept of delay-of-disruption gradient to responding in FI schedules by partially supporting Elcoro's (2005) results. Specifically, in both experiments, the most consistent disruptions of temporal control occurred when response-independent food was delivered closer to the temporally controlled behavior. This finding is further evidence that the temporal proximity of responseindependent food and temporally controlled behavior is an important variable to determine the resistance of temporally controlled behavior to change.

Before placing the present research into a broader theoretical and applied context, some of the procedural aspects and results of the present experiments will be contrasted to previous research on resistance to change and temporal control. The procedural aspects may partly account for the present results and might be modified in future experiments to extend and clarify further questions posed by the present findings. The first aspect refers to the schedule of reinforcement used to generate responding, the FI schedule. This schedule has not been commonly used in resistance-to-change studies, thus it is important to examine the structure and organization of FI responding to better understand how they are affected by responseindependent food. The second aspect is the temporal separation between response-independent food and temporally controlled behavior. This entails a discussion of delay-of-disruption gradients generated by varying both the location and frequency of response-independent food as 
variables that differentially affect temporal control. The third aspect is the ITI duration, which did not produce systematic changes in the present experiments. The fourth aspect is that of the baseline performance. Specifically, how different overall response rates and response patterns modulate outcomes both here and in previous related research.

\section{Fixed-Interval Schedules}

In resistance-to-change studies VI schedules have been used almost exclusively to generate responding that is the dependent variable for tests of resistance to change. In the present experiments, FI schedules, rather than VIs, were used to generate responding so that the strength of response patterns could be assessed (cf. Grace \& Nevin, 2000). These patterns were considered to be instances of temporally organized behavior. The difference between these two schedules is that in VI schedules a reinforcer is delivered following the first response after an average interreinforcer time lapses, while in FI the interreinforcer interval is fixed. As is well known, such difference between the two schedules results in different response patterns.

Variable-interval schedules typically sustain steady, consistent responding. Because there are short inter-reinforcement intervals (IRIs) in VI schedules, inconsistent responding could lead to loss of reinforcement. Thus, rates and patterns of responding in a VI schedule affect more directly the obtained rate of reinforcement than does responding during an FI schedule (Mazur, 2006). Fixed-interval schedules engender more variability between trials (or onsets of intervals) than responding VI in schedules. Thus, optimal rates of reinforcement may be obtained over a wide range of response rates and patterns (e.g., scalloped, or break-and-run) (da Silva, 2001; Zeiler, 1977).

The previously described characteristics of FI responding may contribute to the general variability observed in the present experiments. Another source of variability may be the 
different durations of the FI schedules used in Experiments 1 and 2. The scalar property of timing states that the mean and standard deviation of temporal estimates are proportional to the duration to be timed (Gibbon, 1977). Because of this, responding during a longer-duration FI will be more variable than responding during a shorter-duration FI. Peak functions used to describe the patterns developed on peak trials were wider in a PIP with an FI $30 \mathrm{~s}$ than in a PIP with an FI 10 s (Grace \& Nevin, 2000). By the same token, Lieving (2003) suggested that longer-duration FIs may produce weaker stimulus control than shorter-duration FIs. Consistent with these earlier findings, in the present experiments responding maintained by an FI 30-s schedule was more frequently and markedly disrupted by response-independent food than was responding maintained by an FI 150-s schedule.

It could be said, with some reservation because of the between-subject nature of the comparisons, that the less-variable responding generated by FI $30 \mathrm{~s}$ was less resistant to change than more variable behavior generated by FI $150 \mathrm{~s}$. This difference seems related to research conducted by Doughty and Lattal (2001), who found that more variable behavior was more resistant to disruption than was less variable behavior. The variable behavior in Doughty and Lattal's research was a varied sequence of keypecks, which could be considered analogous to responding in FI $150 \mathrm{~s}$, and the less variable behavior was a repeated sequence of keypecks, which in turn could be considered analogous to responding in FI $30 \mathrm{~s}$. It thus may be reasonable to suggest that in training temporally controlled behavior, such as following an academic schedule, it is valuable to include a certain level of variability (which may be understood as flexibility) that will lead to more resistance to change instead of more rigid routines that could be less resistant to change. 
Delays Between Response-Independent Food and Temporally Controlled Responding

The independent variable of interest in the present experiments was the delay between response-independent food and temporally controlled behavior. Varying the location of response-independent food delivered within FIs preceding a peak trial produced differential disruptions of temporally controlled behavior during the subsequent peak trial (Elcoro, 2005). In the present experiment the delivery of response-independent food occurred as in earlier resistance-to-change studies, within an ITI. It differed from these earlier studies in that it occurred at different locations within the ITI, as in Elcoro, to determine whether these locations would differentially affect FI responding.

\section{Delay-of-Disruption Gradients}

When response-independent food was delivered directly during FI schedules, that is, when there was a delay of zero between response-independent food and temporally controlled behavior, response patterns changed from positively accelerated to linear (Lattal \& Bryan, 1976). Such disruption of temporal control was reliable and maintained for as long as the responseindependent food remained in effect. Also, as the delay between the disrupter and temporal control increases disruption of temporally controlled behavior decreases (Elcoro, 2005).

Partial support for delay-of-disruption gradients was provided by the fact that responseindependent food delivered at the end of the ITI tended to follow the greatest changes in response patterns in Experiment 2; this parallels the findings by Elcoro (2005). The changes in response patterns from positively accelerated to more linear were more frequent and pronounced during the Beginning condition in Experiment 2 than in Experiment 1. This could be related to the fact that during the Beginning condition in Experiment 2, response-independent food occurred immediately after the delivery of the reinforcer, and in Experiment 1 there was a 20-s 
ITI between the reinforcer and response-independent food. The proximity between responseindependent food and reinforcer could have increased its disruptive effects, but it is not clear how. If the occurrence of a response followed by a reinforcer becomes more likely as the time for reinforcement elapses, how can response-independent food located after and proximal to that reinforcer, increased the probability of responding even more so responding occurred earlier in the interval? One possibility is that such increased responding could be due in part to the discriminative control exerted by response-independent food as described by Lattal and AbreuRodrigues (1997). This discriminative control occurs when a disrupter such as responseindependent food consists of the same food used as a reinforcer. Just as the reinforcer, such response-independent food may evoke further operant responding.

Counter to the previous account; if response-independent food is closer to the reinforcer, it could more likely come to function as part of the reinforcer. If such is the case, it could function as an increase in reinforcement magnitude. Thus, the proximity between reinforcer and response-independent food could have in turn resulted in longer PRPs, as was found when reinforcement magnitude was increased in FI schedules by Blomeley, Lowe, and Wearden (2004) and more pronounced positively accelerated patterns of responding (as the increased run rates as a function of increased reinforcement magnitude found also by Blomeley et al.), but that did no occur in the present experiments. It could be argued that even though reinforcer and response-independent food were close to each other, the increased access to food was responseindependent and thus was not correlated with reinforcement by temporal proximity.

\section{Response-Independent Food Delivery}

To account for some of the present results it is also pertinent to consider how responseindependent food was delivered in the present experiments. Such food frequently increased 
overall response rates, as observed for Pigeon 2403 during the Beginning condition with both ITI durations and for Pigeon 761 during all conditions in which response-independent food was delivered. Such increased responding could be due in part to the discriminative control exerted by response-independent food described earlier (Lattal \& Abreu-Rodrigues, 1997). The increase in response rates also has been suggested by increased arousal (Killeen et al., 1978) produced by the motivational change involved in increasing access to food (Shull, 2004; Ward \& Odum, 2006). These increased response rates sometimes diminished over time (e.g., Pigeon 2403 in both Beginning conditions), suggesting decreased arousal.

Within-session recovery of responding also was observed in both of the present experiments. For example, during the End condition in Experiment 1 Pigeon 840 when the ITI was 135 s (see Figure 4) and Experiment 2 Pigeon 999 when the ITI was 35 s (see Figure 8). As shown in Figures 4 and 8 responding along the FI was mostly disrupted during the initial part of the session and recovered as the session progressed. Such recovery shows that disruption in resistance-to-change studies involve local changes in patterns and response rates that are not well captured by dependent measures that collapse data of one session such as overall response rates.

The arrangement of response-independent food in these experiments differed from its arrangement in previous studies where it was used to assess resistance to change. It typically has consisted of a single food presentation scheduled according to a VT schedule such that the food deliveries are scattered more or less variably across the ICIs separating the multiple schedule components. Lieving (2003) found that as the frequency of VT food delivered during the ICI of a FOPP increased, the ET50s tended to decrease. The distribution of disrupters differentially affects responding maintained by a VI schedule when the disrupters are imposed during the schedule itself, as opposed to being in the ICI (Lattal \& Abreu-Rodrigues, 1997). Lattal and 
Abreu-Rodrigues used FT or FI schedules to intrude food in VI schedules. Both response rates and response patterns were differentially disrupted. Based on Elcoro's (2005) results and those of the present experiments, as response-independent food is closer to the onset of an FI, the disruption of temporal control of that upcoming FI is greater.

In the present experiments, five successive response-independent food deliveries spaced $2 \mathrm{~s}$ apart served as the disrupter. Whether there is a difference in disruption as a function of massed versus the more typically studied spaced disrupters (e.g., Nevin, 1974; 1979) remains unexplored. If the onset of each response-independent food delivery is similar to the onset of action of drugs as a main contributor to its effects (Balster \& Schuster, 1973; Panlilio, Goldberg, Gilman, Jufer, Cone, \& Schindler, 1998; Winger, Hursh, Casey, \& Woods, 2002) then, multiple onsets of each response-independent food delivery in the present experiments can be thought of as more disruptive than less frequent onsets.

\section{Effects of ITI/ICI Duration}

In previous resistance-to-change studies the durations of ICIs used to deliver responseindependent food typically have been short (e.g., 10-20 s). In the present experiments the ITI durations in which response-independent food was delivered were longer and were changed across conditions. These changes were based on research, described in the literature review, that shows differential effects of ITI duration on temporal control and the speed of acquisition of a keypeck (Bizo \& White, 1994a, 1994b; Ferster \& Skinner, 1957; Gibbon et al., 1977; Terrace et al., 1975).

Despite prior evidence of a difference in responding as a function of ITI duration, no consistent differences in responding occurred as a function of the ITI in the present experiments. The ITIs (35 and $135 \mathrm{~s}$ ) may both have been past the point on the ITI continuum where 
differences in ITI values control differential response rates. It could be that the disruptive effects of response-independent food operate in a fashion as shown in Figure 9. As the ITI duration increases ( $\mathrm{x}$ axis) in the figure, disruption decreases (y axis). The present relation between ITI duration and disruption was different from the relation found by Gibbon et al. (1977) and Terrace et al. (1975) in an autoshaping procedure: as the ITI duration increased the speed of acquisition increased. In the case of acquisition in autoshaping, the ITI duration may increase the discriminability of trials, and that may facilitate acquisition. In the case of disruption, however, if the ITI in which the disrupters are delivered is too distinct from, in the present experiments, the FI schedule, then the entire procedure might function as a multiple schedule in which each component is under a level of stimulus control that results in minimal interaction between components.

\section{Baseline Differences: Overall Response Rates and Patterns}

Disruptive effects in the present experiments were related to baseline overall response rates. In Experiment 1, overall response rates during baseline conditions ranged between 35.47 and 69.22 responses per min. Similarly, Pigeons 670 and 761 in Experiment 2 had overall response rates during baseline conditions of between 9.10 and 77.19 responses per min. For all pigeon s in Experiment 1 and the two pigeons from Experiment 2 noted above, the effects of response-independent food on overall response rates were less consistent than they were for Pigeons 669 and 999 in Experiment 2 (their overall response rates during baseline conditions ranged between $104.01-158.93 \mathrm{Resp} / \mathrm{min})$. The difference between these two last pigeons and the others is that their base overall response rates were higher. This is consistent with Lattal's (1989) finding that lower response rates are more resistant to change. 


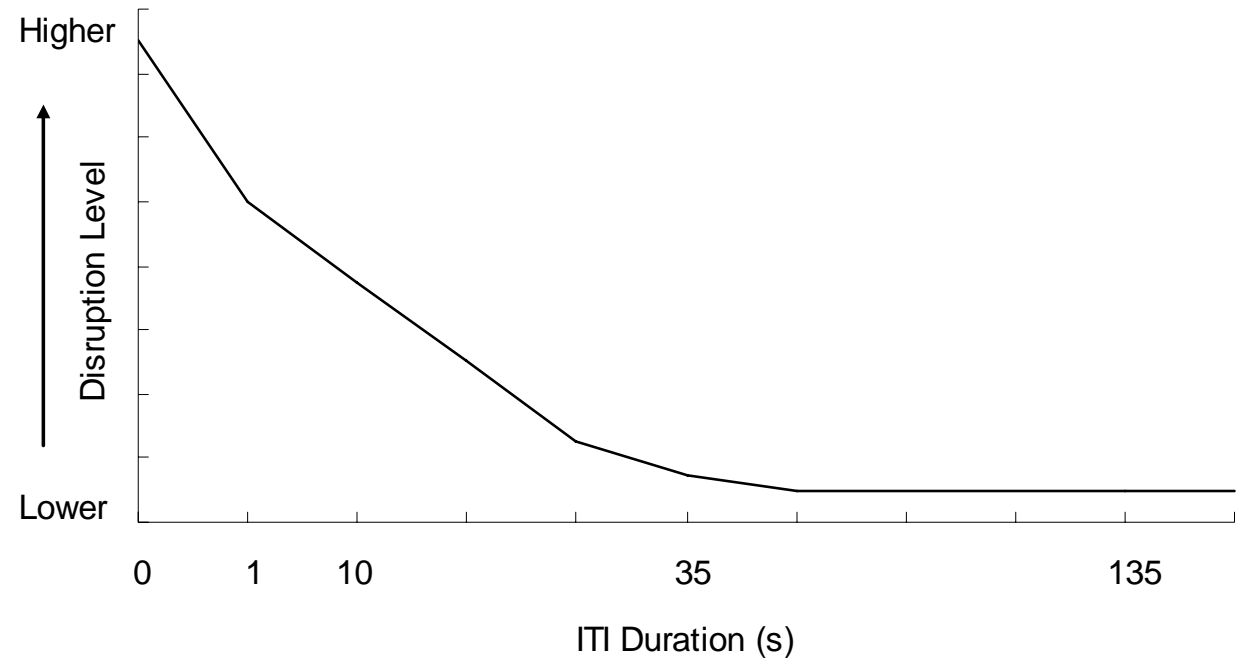

Figure 9. Hypothetical representation of disruption levels (y axis) as a function of ITI duration (x axis) 
Lower response rates could be considered more efficient than higher response rates in FI schedules because only a single response is required to earn a reinforcer. Pigeons 670 and 761 had lower overall response rates and higher QL values $(0.53-0.77)$ during baseline conditions preceding the delivery of response-independent food than Pigeons 999 and $669(0.43-0.60)$ which had higher response rates. The pigeons in Experiment 1 had baseline QL values that ranged between 0.45 and 0.63 , and also lower response rates than Pigeons 670 and 761 . These QL values could be related to the variability related to the FI duration described earlier. The relatively smaller changes in QL values as a function of response-independent food in Experiment 1 compared to Experiment 2 could be also due to a floor effect given that QL values were somewhat lower to begin with $\left(M_{E x p 1}=0.55, M_{E x p 2}=0.61\right)$.

Implications of the Results for the Study of Complex Operants

The analysis of behavior involves its deconstruction (Thompson \& Lubinski, 1986). To understand the mechanism involved in the origin and maintenance of response patterns in FI schedules, these patterns have been analyzed subjecting them to disruptive operations that attempt to disorganize them. Dews conducted a series of experiments $(1962,1964,1965,1966)$ to elucidate the underlying mechanism of temporal control by examining how FI response patterns would sustain the intrusion of different exteroceptive stimuli. The study of the changes that response patterns undergo is useful in further understanding the cohesiveness of temporal control; it reveals how the patterns change and their resilience to such changes.

\section{Response Patterns as Behavioral Units}

The conceptualization of phenomena in a science of behavior, as in any science, can only take place with a clearly defined and meaningful unit of analysis (Findley, 1962; Zeiler, 1986). The response patterns that develop in FI schedules have been suggested to be behavioral units in 
that they are an integrated sequence of responses extended in time with a common function (Hawkes \& Shimp, 1975). These response patterns are controlled by the temporal regularity of the reinforcer (Zeiler, 1977).

The idea of response patterns as a complex unit arises from an abstraction or model of a unit (Thompson \& Lubinski, 1986). An example of one such complex unit is the scallop, questioned for being an artifact of aggregated data, but empirically established as an actual pattern evidenced within single FIs (Gollub, 1964; Wearden \& Lejeune, 2006). The scallop, however, is not the only pattern generated by FI schedules. Patterns developed by FI schedules vary, as specified in the literature review, there is no such thing as the FI response pattern, and such is also the case with a simple operant response.

Complex units of behavior are similar to simple units in the sense that both are affected similarly by schedules of reinforcement (Kelleher, 1966; Zeiler, 1977). If complex units share the characteristics of simple units, then why is the distinction between these two units necessary or helpful? The possibility of compounding simple operants into a complex unit allows for versatility of analysis in the sense that the complex unit can capture a wider variety of naturally occurring behaviors of interest in the basic and applied fields of behavior analysis. The similarity between the units can also be viewed as an analytical advantage that provides a common level of discourse to understand complex and simple units of behavior.

The similarity between complex and simple units previously described also allows for application of procedures that affect simple operants to complex operants (e.g., Doughty \& Lattal, 2001), such as resistance-to-change procedures. Most of the studies on resistance-tochange have examined simple operants. Few researchers such as Doughty and Lattal; Grace and 
Nevin (2000); Elcoro (2005) and Lieving (2003) and the present experiments have used these resistance-to-change procedures to examine complex units of behavior.

Frequently, the disruption observed with these resistance-to-change procedures when examining simple operants is in the form of a decrease in response rates. Other dependent measures used to examine complex operants such as those developing with procedures to generate temporal control are peak rates, QL values, and ET50s might not necessarily decrease as a function of a resistance-to-change test. Indeed, they might increase (e.g., as in underestimation of time reflected by increased ET50s).

To characterize the disruption of temporal control it is important to first understand the response patterns before disruption. The initial exposures to an FI schedule are characterized by evenly distributed response across the interval (Ferster \& Skinner, 1957; Zeiler, 1977). The acquisition of FI responding involves the lengthening of the PRP, which means that the period of responding is reciprocally decreased, an effect of confinement (Wearden \& Lejeune, 2006). After repeated exposure to the FI, the positively accelerated pattern of responding emerges. In this pattern, most of the single responses progressively accumulate close to the delivery of the reinforcer.

The internal cohesiveness of the response patterns developed in FI schedules has been subjected to different tests of its unity. Some of these tests involved the intrusion of direct changes within ongoing operant responding (e.g., Lattal \& Bryan, 1976); others involved more remote changes relative to temporally controlled responding (e.g., Elcoro, 2005; and the present experiments). The examination of the internal consistency of these patterns by more remote (also referred to as indirect) changes was the general purpose of the present research. 
One of the most common changes observed in response patterns in the present experiments was that from positively accelerated to more linear as a function of the delivery of response-independent food during the beginning and the end condition. This change was reflected by an increase in responding during the initial segment of the FI in which there were very few or no responses during baseline condition. It could be said that the PRP, the time in which those response occur as a result of disruption, is the weakest part of the interval because it is the furthest from the delivery of the reinforcer, and thus where the least responding occurs. The initial part of the interval was more susceptible to changes induced by response-independent food. The disruption is reflected by a disorganization of the pattern; responding instead of being only concentrated around the time when the reinforcer is delivered, is redistributed along the interval.

\section{Application of Delay-of-Disruption Gradients}

As mentioned earlier, an advantage of examining complex operants is that they seem to mirror other forms of temporally integrated response patterns that occur in a variety of settings. In this way, the study of complex operants in the laboratory may contribute to fleshing out the connection between basic and applied behavior analysis (Mace, 1994). The aim of this section is to offer two examples that take place in settings other than the laboratory in which the temporal location of a disrupter would likely contribute in determining the resistance of previously established temporally controlled behavior.

An example of temporally controlled behavior such as a temper tantrum in a child consists of a series of topographically distinct responses (e.g., screaming, kicking, crying) extended in time with a unifying function (e.g., attention, escape). If an unexpected event such as an argument between the parents of the child happens right before the onset of the temper 
tantrum, such event may exacerbate the tantrum. An unexpected event such as the onset of a favorite television show (for the child) before the temper tantrum might change the organization of the tantrum in a different way, maybe making it less intense than how it commonly occurs.

Another example of temporally controlled behavior is foraging; an organized sequence of events that involves searching, finding, storing, and ingesting food (Zeiler, 1986). The temporal location of a disrupter, such as the presence of a predator, before the foraging sequence commences, may differentially affect the organization of foraging. Such disrupter may cause a visit to a different patch, maybe a closer or further one that might not offer the same quality of food provided by the one that would be originally visited. Further investigation on effects of the location of disrupters on temporally controlled behavior will extend the generality of the concept of delay-of-disruption gradient to other settings.

\section{Conclusion}

Effects of response-independent food were more frequently observed and differed according to their temporal location in Experiment 2 and not in Experiment 1. In Experiment 2, when response-independent food was located at the end of the ITI, the QL values of the first session in which response-independent food was delivered were lower than when the responseindependent food was located at the beginning of the ITI. Response patterns tended to yield higher QL values towards the last session in which response-independent food was delivered (regardless of its location) demonstrating recovery. The fact that response-independent food delivered at the end of the ITI produced the most pronounced changes in response patterns partially supported the findings by Elcoro (2005) thus extending the generality of the concept of delay-of-disruption gradient. The fact that more frequent and consistent changes upon the delivery of response-independent food during Experiment 2 and not for Experiment 1 suggests 
that a shorter-duration FI such as FI $30 \mathrm{~s}$ was more sensitive to changes than a longer-duration FI such as FI $150 \mathrm{~s}$. 


\section{REFERENCES}

Balster, R. L., \& Schuster, C. R. (1973). Fixed-interval schedule of cocaine reinforcement: Effect of dose and infusion duration. Journal of the Experimental Analysis of Behavior, 20, 119129.

Bizo, L. A., \& White, K. G. (1994a). Pacemaker rate in the behavioral theory of timing. Journal of Experimental Psychology: Animal Behavior Processes, 20, 308-321.

Bizo, L. A., \& White, K. G. (1994b). The behavioral theory of timing: Reinforcer rate determines pacemaker rate. Journal of the Experimental Analysis of Behavior, 61, 19-33.

Blomeley, F. J., Lowe, C. F., \& Wearden, J. H. (2004). Reinforcement concentration effects on a fixed-interval schedule. Behavioural Processes, 67, 55-66.

Brown, P. L. \& Jenkins, H. M. (1968). Autoshaping of the pigeon's key-peck. Journal of the Experimental Analysis of Behavior, 11, 1-8.

Catania, C. (1991). Time as a variable in behavior analysis. In I. H. Iversen, \& K. A. Lattal (Eds.), Experimental analysis of behavior: Part I (pp. 1-19). New York: Elsevier Science.

Church, R. M. (2002). A tribute to John Gibbon. Behavioural Processes, 57, 261-274.

Cumming, W. W., \& Schoenfeld, W. N. (1958). Behavior under extended exposure to a highvalue fixed interval reinforcement schedule. Journal of the Experimental Analysis of Behavior, 1, 245-263.

da Silva, S. P. (2001). Fixed-interval performance as a function of previous temporal discrimination training. Unpublished Master's thesis. West Virginia University, Morgantown. https://eidr.wvu.edu/eidr/documentdata.eIDR?documentid=1968

da Silva, S. P., \& Lattal, K. A. (2006). Contextual determinants of temporal control: Behavioral contrast in a free-operant. Behavioural Processes, 71, 157-163. 
Dews, P. B. (1962). The effect of multiple $\mathrm{S}^{\Delta}$ periods on responding on a fixed-interval schedule. Journal of the Experimental Analysis of Behavior, 5, 369-374.

Dews, P. B. (1965). The effect of multiple $\mathrm{S}^{\Delta}$ periods on responding on a fixed-interval schedule: III. Effect of changes in pattern of interruptions, parameters and stimuli. Journal of the Experimental Analysis of Behavior, 8, 427-435.

Dews, P. B. (1966). The effect of multiple $\mathrm{S}^{\Delta}$ periods on responding on a fixed-interval schedule: V. Effect of periods of complete darkness and of occasional omissions of food presentations. Journal of the Experimental Analysis of Behavior, 9, 573-578.

Dews, P. B. (1970). The theory of fixed-interval responding. In W. N. Schoenfeld (Ed.). The theory of reinforcement schedules (pp. 43-61). New York: Appleton-Century-Crofts.

Dews, P. B. (1978). Studies on responding under fixed-interval schedules of reinforcement: II. The scalloped pattern of the cumulative record. Journal of the Experimental Analysis of Behavior, 29, 67-75.

Doughty, A. H., \& Lattal, K. A. (2001). Resistance to change of operant variation and repetition. Journal of the Experimental Analysis of Behavior, 76, 195-215.

Drew, M. R., Fairhurst, S., Malapani, C., Horvitz, J. C., \& Balsam, P. D. (2003). Effects of dopamine anatagonists on the timing of two intervals. Pharmacology, Biochemistry and Behavior, 75, 9-15.

Elcoro, M. (2005). Resistance of temporally controlled behavior to change. Unpublished Master's thesis. West Virginia University, Morgantown. https://eidr.wvu.edu/etd/filelist.eTD?documentid=4363

Farmer, J., \& Schoenfeld, W. N. (1966). Varying temporal placement of an added stimulus in a fixed-interval schedule. Journal of the Experimental Analysis of Behavior, 9, 369-375. 
Ferster, C. B., \& Skinner, B. F. (1957). Schedules of reinforcement. Copley, MS: Acton.

Findley, J. D. (1962). An experimental outline for building and exploring multi-operant behavior repertoires. Journal of the Experimental Analysis of Behavior, 5, 113-116.

Fry, W., Kelleher, R. T., \& Cook, L. (1960). A mathematical index of performance on fixedinterval schedules of reinforcement. Journal of the Experimental Analysis of Behavior, 3, 193-199.

Gibbon, J. (1971). Scalar timing and semi-Markov chains in free-operant avoidance. Journal of Mathematical Psychology, 8, 109-138.

Gibbon, J. (1972). Timing and discrimination of shock density in avoidance. Psychological Review, 84, 279-325.

Gibbon, J. (1977). Scalar expectancy theory and Weber's law in animal timing. Psychological Review, 84, 279-325.

Gibbon, J., Baldock, M. D., Locurto, C., Gold, L., \& Terrace, H. S. (1977). Trial and intertrial durations in autoshaping. Journal of Experimental Psychology: Animal Behavior Processes, 3, 264-284.

Gibbon, J., \& Balsam, P. (1981). Spreading association in time. In C. M. Locurto, H. S. Terrace, \& J. Gibbon (Eds.), Autoshaping and conditioning theory (pp. 219-253). New York: Academic Press.

Gilbert, T. F. (1958). Fundamental dimensional properties of the operant. Psychological Review, 65, 272-282.

Gollub, L. R. (1964). The relations among measures of performance on fixed-interval schedules. Journal of the Experimental Analysis of Behavior, 7, 337-343. 
Grace, R. C., \& Nevin, J. A. (2000). Response strength and temporal control in fixed-interval schedules. Animal Learning andBehavior, 28, 313-331.

Hawkes, L., \& Shimp, C. P. (1975). Reinforcement of behavioral patterns: Shaping a scallop. Journal of the Experimental Analysis of Behavior, 23, 3-16.

Herrnstein, R. J., \& Morse, W. H. (1957). Effects of pentobarbital on intermittently reinforced behavior. Science, 125, 929-931.

Higa, J. J. (1998). Interval timing: Is there a clock? Behavioural Processes, 44, 87-88.

Higa, J. J., \& Pierson, D. (1998). Temporal control in rats: Analysis of nonlocalized effects from short interfood intervals. Journal of the Experimental Analysis of Behavior, 70, 35-43.

Innis, N. K., Mitchell, S. K., \& Staddon, J. E. R. (1993). Temporal control on interval schedules: what determines the postreinforcement pause? Journal of the Experimental Analysis of Behavior, 60, 293-311.

Kelleher, R. T. (1966). Chaining and conditioned reinforcement. In W. K. Honig (Ed.), Operant behavior: Areas of research and application (pp. 160-212). New York: AppletonCentury-Crofts.

Killeen, P. R., \& Fetterman J. G. (1988). A behavioral theory of timing. Psychological Review, 95, 274-295.

Killeen, P. R., Hanson, S. J., \& Osborne, S. R. (1978). Arousal: Its genesis and manifestation as response rate. Psychological Review, 85, 571-581.

Lattal, K. A. (1989). Contingencies on response rate and resistance to change. Learning and Motivation, 20, 191-203.

Lattal, K. A., \& Abreu-Rodrigues, J. (1997). Response-independent events in the behavior stream. Journal of the Experimental Analysis of Behavior, 68, 375-398. 
Lattal, K. A., \& Bryan, A. J. (1976). Effects of concurrent response-independent reinforcement on fixed-interval schedule performance. Journal of the Experimental Analysis of Behavior, 26, 495-504.

Levin, E. D., Conners, C. K., Sparrow, E., Hinton, S. C., Erhardt, D. Meck, W. H., et al. (1996). Nicotine effects on adults with attention-deficit/hyperactivity disorder. Psychopharmacology, 123, 55-63.

Levin, E. D., Conners, C. K., Silva, D., Hinton, S. C., Meck, W. H., March, J., et al. (1998). Transdermal nicotine effects on attention. Psychopharmacology, 140, 135-141.

Lieving, L. (2003). Temporal control and response strength in a free-operant psychophysical procedure. Unpublished Doctoral Dissertation. West Virginia University, Morgantown. https://eidr.wvu.edu/eidr/documentdata.eIDR?documentid=3102

Mace, F. C. (1994). Basic research needed for stimulating the development of behavioral technologies. Journal of the Experimental Analysis of Behavior, 61, 529-550.

Malapani, C., \& Fairhurst, S. (2002). Scalar timing in animal and humans. Learning \& Motivation, 33, 156-176.

Mazur, J. E. (2006). Learning and behavior (6 $6^{\text {th }}$ Ed.). New Jersey: Pearson Prentice Hall. Meck, W. H. (2003). Introduction: The persistence of time. In W. H. Meck (Ed.), Functional and neural mechanisms of interval timing (pp. xvii-xli). Boca Raton, FL: CRC Press.

Nevin, J. A. (1974). Response strength in multiple schedules. Journal of the Experimental Analysis of Behavior, 21, 389-408.

Nevin, J. A. (1979). Reinforcement schedules and response strength. In M. D. Zeiler, \& P. Harzem (Eds.), Reinforcement and the organization of behavior (pp. 117-158). Chichetser, England: Wiley. 
Nevin, J. A., \& Grace, R. C. (2000). Behavioral momentum and the law of effects. Behavioral and Brain Sciences, 23, 73-130.

Nevin, J. A., Mandell, C., \& Atak, J. R. (1983). The analysis of behavioral momentum. Journal of the Experimental Analysis of Behavior, 39, 49-59.

Nevin, J. A., Milo, J., Odum, A. L., \& Shahan, T. A. (2003). Accuracy of discrimination, rate of responding, and resistance to change. Journal of the Experimental Analysis of Behavior, 79, 307-321.

Panlilio, L. V., Goldberg, S. R., Gilman, J. P., Jufer, R., Cone, E. J., \& Schindler, C. W. (1998). Effects of delivery rate and non-contingent infusion of cocaine on cocaine selfadministration in rhesus monkeys. Psychopharmacology, 137, 253-258.

Papini, M. R., \& Hollingsworth, P. R. (1998). Role of nonreinforcement in the fixed-interval performance of pigeons. Psychonomic Bulletin and Review, 5, 84-90.

Reilly, M., \& Lattal, K. A. (2004). Within-session delay-of-reinforcement gradients. Journal of the Experimental Analysis of Behavior, 82, 21-35.

Reynolds, G. S., \& Catania, C. (1961). Behavioral contrast with fixed-interval and low-rate reinforcement. Journal of the Experimental Analysis of Behavior, 4, 387-391.

Richards, R. W. (1981). A comparison of signaled and unsignaled delay of reinforcement. Journal of the Experimental Analysis of Behavior, 35, 145-152.

Richelle, M., \& Lejeune, H. (1980). Time in animal behaviour. New York: Pergamon Press. Roberts, S. (1981). Isolation of an internal clock. Journal of Experimental Psychology: Animal Behavior Processes, 7, 242-268. 
Schaal, D. W., \& Branch, M. N. (1990). Responding of pigeons under variable-interval schedules of signaled-delayed reinforcement: Effects of delay-signal duration. Journal of the Experimental Analysis of Behavior, 53, 103-121.

Schaal, D. W., Odum, A. L., \& Shahan, T. A. (2000). Pigeons may not remember the stimuli that reinforced their recent behavior. Journal of the Experimental Analysis of Behavior, 73, 125-139.

Schneider, B. A. (1969). A two-state analysis of fixed-interval responding in the pigeon. Journal of the Experimental Analysis of Behavior, 12, 677-687.

Shull, R. L. (2004). Bouts of responding on variable-interval schedules: Effects of deprivation level. Journal of the Experimental Analysis of Behavior, 81, 155-167.

Sizemore, O. J., \& Lattal, K. A. (1978). Unsignalled delay of reinforcement in variable-interval schedules. Journal of the Experimental Analysis of Behavior, 30, 169-175.

Skinner, B. F. (1935). The generic nature of the concepts of stimulus and response. Journal of General Psychology, 12, 40-65.

Skinner, B. F. (1938). The behavior of organisms. New York: Appleton-Century-Crofts.

Staddon, J. E. R., Cheralu, I. M., \& Higa, J. J. (2002). A tuned-trace theory of interval-timing dynamics. Journal of the Experimental Analysis of Behavior, 77, 105-124.

Staddon, J. E. R., \& Innis, N. K. (1966) Preference for fixed vs. variable amounts of reward. Psychonomic Science, 4, 193-194.

Terrace, H. S., Gibbon, J., Farrell, L., \& Baldock, M. D. (1975). Temporal factors influencing the acquisition and maintenance of an autoshaped keypeck. Animal Learning \& Behavior, 3, 53-62. 
Thompson, T., \& Lubinski, D. (1986). Units of analysis and kinetic structure of behavioral repertoires. Journal of the Experimental Analysis of Behavior, 46, 219-242.

Tonneau, F., Rios, A., \& Cabrera, F. (2006). Measuring resistance to change at a within-session level. Journal of the Experimental Analysis of Behavior, 86, 109-121.

Ward, R. D., \& Odum, A. L. (2006). Effects of prefeeding, inter-component interval food, and extinction on temporal discrimination. Behavioural Processes, 71, 297-306.

Wearden, J. H., \& Lejeune, H. (2006). "The stone which the builders rejected...”: Delay of reinforcement and response rate on fixed-interval and related schedules. Behavioural Processes, 71, 77-87.

Winger, G., Hursh, S. R., Casey, K. I., \& Woods, J. H. (2002). Relative reinforcing effects of three NMDA antagonists with different onsets of action. Journal of Pharmacology and Experimental Therapeutics, 301, 690-697.

Zeiler, M. D. (1977). Schedules of reinforcement, the controlling variables. In W. K. Honig \& J. E. R. Staddon (Eds.), Handbook of operant behavior (pp. 201-232). New Jersey: Prentice Hall.

Zeiler, M. D. (1986). Behavior units and optimality. In T. Thompson \& M. D. Zeiler (Eds.), Analysis and integration of behavioral units. (pp.81-116). New Jersey: Lawrence Erlbaum Associates, Publishers.

Zeiler, M. D., \& Powell, D. G. (1994). Temporal control in fixed-interval schedules. Journal of the Experimental Analysis of Behavior, 61, 1-10. 